\title{
Sensitivity of Monthly Convective Precipitation to Environmental Conditions
}

\author{
BOKSOON MYOUnG AND JOHN W. NIELSEN-GAMMON \\ Department of Atmospheric Sciences, Texas A\&M University, College Station, Texas
}

(Manuscript received 14 August 2008, in final form 5 August 2009)

\begin{abstract}
Identifying dynamical and physical mechanisms controlling variability of convective precipitation is critical for predicting intraseasonal and longer-term changes in warm-season precipitation and convectively driven large-scale circulations. On a monthly basis, the relationship of convective instability with precipitation is examined to investigate the modulation of convective instability on precipitation using the Global Historical Climatology Network (GHCN) and NCEP-NCAR reanalysis for 1948-2003. Three convective parametersconvective inhibition (CIN), precipitable water (PW), and convective available potential energy (CAPE)are examined. A lifted index and a difference between low-tropospheric temperature and surface dewpoint are used as proxies of CAPE and CIN, respectively.

A simple correlation analysis between the convective parameters and the reanalysis precipitation revealed that the most significant convective parameter in the variability of monthly mean precipitation varies by regions and seasons. With respect to region, $\mathrm{CIN}$ is tightly coupled with precipitation over summer continents in the Northern Hemisphere and Australia, while PW or CAPE is tightly coupled with precipitation over tropical oceans. With respect to seasons, the identity of the most significant convective parameter tends to be consistent across seasons over the oceans, while it varies by season in Africa and South America. Results from GHCN precipitation data are broadly consistent with reanalysis data where GHCN data exist, except in some tropical areas where correlations are much stronger (and sometimes signed differently) with reanalysis precipitation than with GHCN precipitation.
\end{abstract}

\section{Introduction}

\section{a. The ingredients of tropical convection}

Convective precipitation occurs mainly over tropical regions and plays significant roles in the general circulation of the atmosphere and global climate. Thus, identifying the dynamical and physical mechanisms controlling convective precipitation is critical for understanding and predicting the variability of convective precipitation and large-scale circulation on seasonal and climatic time scales.

For example, the impact of anomalous sea surface temperature (SST) associated with El Niño-Southern Oscillation (ENSO) on precipitation has been extensively studied. It has been found that the interannual variability of precipitation is greatly affected by ENSO in the western Pacific, the Asian monsoon region, Australia, and several continental regions (Horel and Wallace 1981; Ropelewski

Corresponding author address: John Nielsen-Gammon, 3150 TAMU, Department of Atmospheric Sciences, Texas A\&M University, College Station, TX 77843-3150.

E-mail: n-g@tamu.edu and Halpert 1987; Chiang and Sobel 2002). Modulation of deep convection constitutes the direct local impact of ENSO as well as the mechanism by which the ENSO signal is communicated to remoter parts of the atmosphere. However, it is still difficult for general circulation models (GCMs) to predict precipitation anomalies owing to the nonlinear response of the atmosphere to ENSO (Mason and Goddard 2001), the nonlinear interactions with sea surface temperature anomalies in the other oceans (e.g., Goddard and Graham 1999), and the inherent unpredictability of the atmosphere.

Raymond et al. (2003) note that many atmospheric factors are correlated with tropical deep convection, but that understanding the thread of causality requires initial examination of those factors that directly and immediately influence deep convection. In broad terms, Raymond et al. identify those factors as the magnitude of convective inhibition (CIN); the magnitude of local triggering disturbances; the characteristics of the lifted air parcel, temperature, moisture, and shear profiles of the environment; and the environmental aerosol population. Other processes make their influence felt by 
(a)

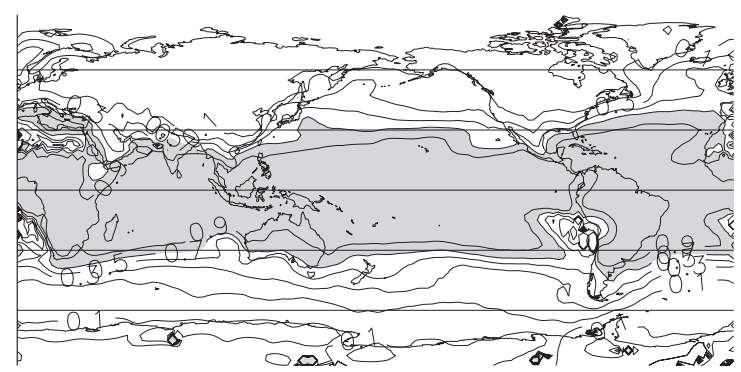

(c)

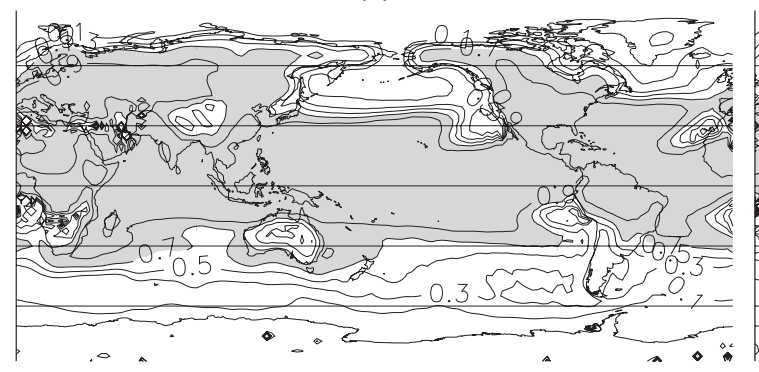

(b)

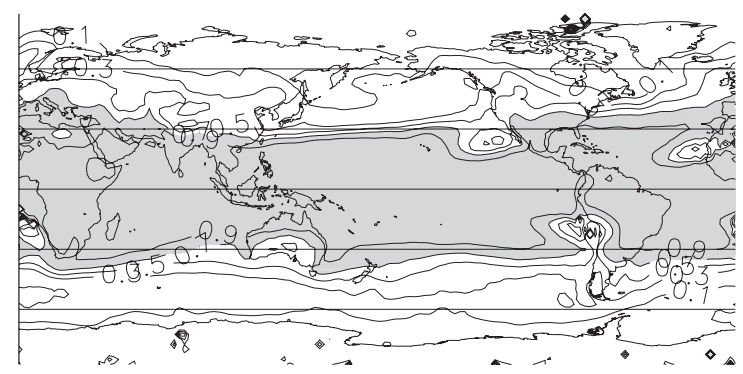

(d)

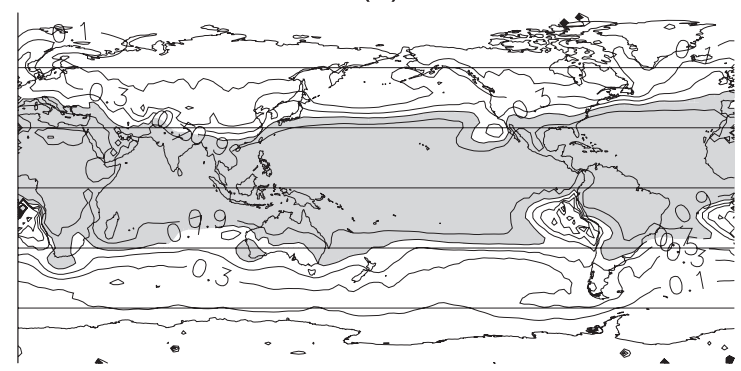

FIG. 1. The ratio of the convective precipitation to the total precipitation in the NCEP-NCAR reanalysis in (a) January, (b) April, (c) July, and (d) October. The ratio greater than 0.7 is shaded and the contour interval is 0.2.

altering one or more of these factors. However, this list of direct environmental influences is too broad for our purposes, and some winnowing is necessary.

Some guidance is available from attempts to forecast midlatitude convection on a day-to-day basis. In this context, three necessary ingredients for deep convection were suggested by Doswell (1987): ample moisture in the lower troposphere, a substantial "positive area" with a steep enough lapse rate, and sufficient lifting. These three ingredients are usually represented by high precipitable water (PW), convective instability, and largeor small-scale lifting mechanisms, respectively.

PW generally has a positive relationship with precipitation (Sato and Kimura 2003; Brenner 2004; Bretherton et al. 2004). Higher PW indicates larger amounts of moisture available to condense and precipitate out and less dry air to be entrained from the midtroposphere. High PW also tends to increase the second ingredient, convective instability.

Convective instability may be assessed by examining convective available potential energy (CAPE), which is the vertical integral of parcel buoyancy between the level of free convection (LFC) and the equilibrium level (EL). Physically, CAPE refers to the maximum kinetic energy per unit mass of air that can be attained by an ideal undiluted ascending air parcel, which means that higher CAPE implies stronger updrafts within the convective towers.

For an ascending parcel to realize positive potential energy above the LFC, it needs to overcome negative energy through the stable layer to reach the LFC. This negative energy is named convective inhibition. Doswell's (1987) third ingredient, a sufficient lifting mechanism, can be restated as a requirement of sufficiently small CIN. (Here, we follow the convention that CIN is positive, so large values of CIN inhibit convection.) Because of CIN, deep convection over oceans as well as over land may be prevented from occurring over a wide area despite the presence of substantial CAPE (Lanicci and Warner 1991; Williams and Renno 1993). In such a case, the parcel needs either sufficient kinetic energy to reach the LFC for deep convection or sufficient large-scale ascent to produce absolute instability from potential instability.

$\mathrm{CIN}$ is a measure of the magnitude of the triggering mechanism needed to initiate convection, but there may also be variations in the magnitude of the triggering mechanism itself. Such triggering may be relatively uniform from day to day, as in the case of the overland diurnal cycle and sea breezes, or it may be quite variable, as in the case of flow over orography or tropical disturbances such as easterly waves.

While the "ingredients" approach was developed for day-to-day precipitation variations, it is applicable on longer time scales as well. Just as daily convective precipitation is directly controlled by such environmental characteristics as CAPE, CIN, and PW, the same must be true on a monthly or seasonal sense. However, the nature of the relationships may change on multiday time scales because the same convection that is initiated by suitable values of the convective parameters in turn alters those 
(a) Jan

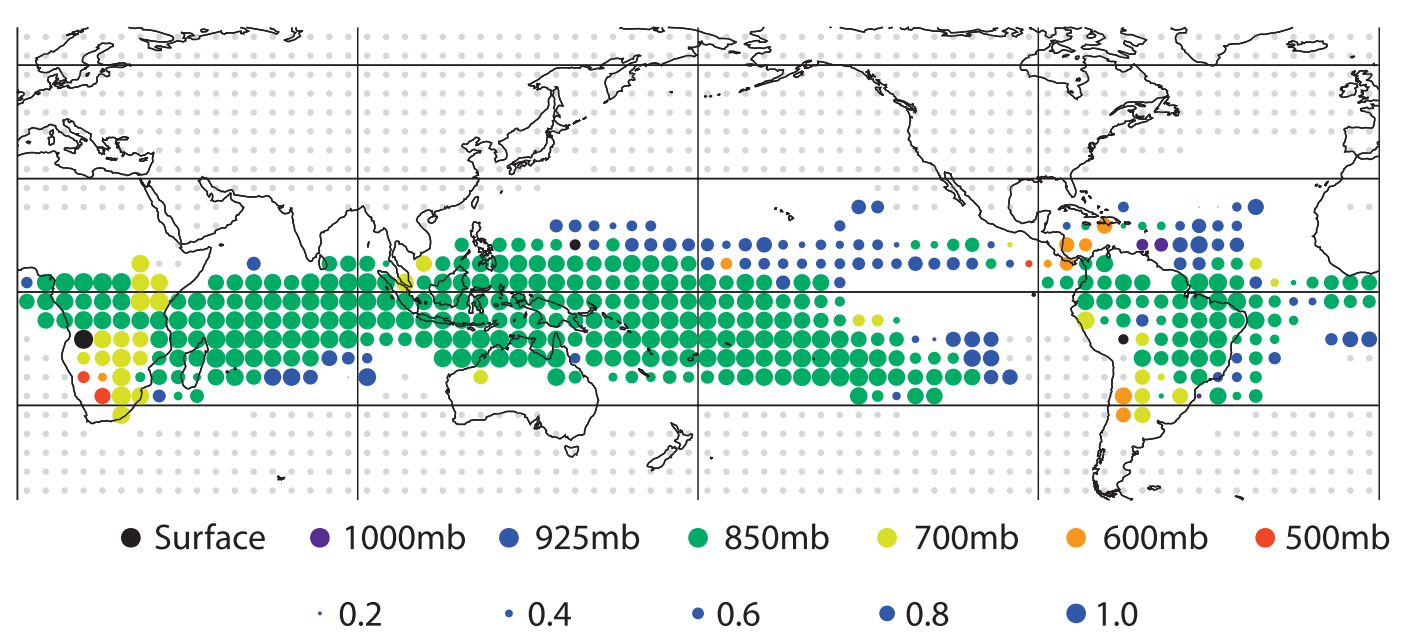

(b) Apr

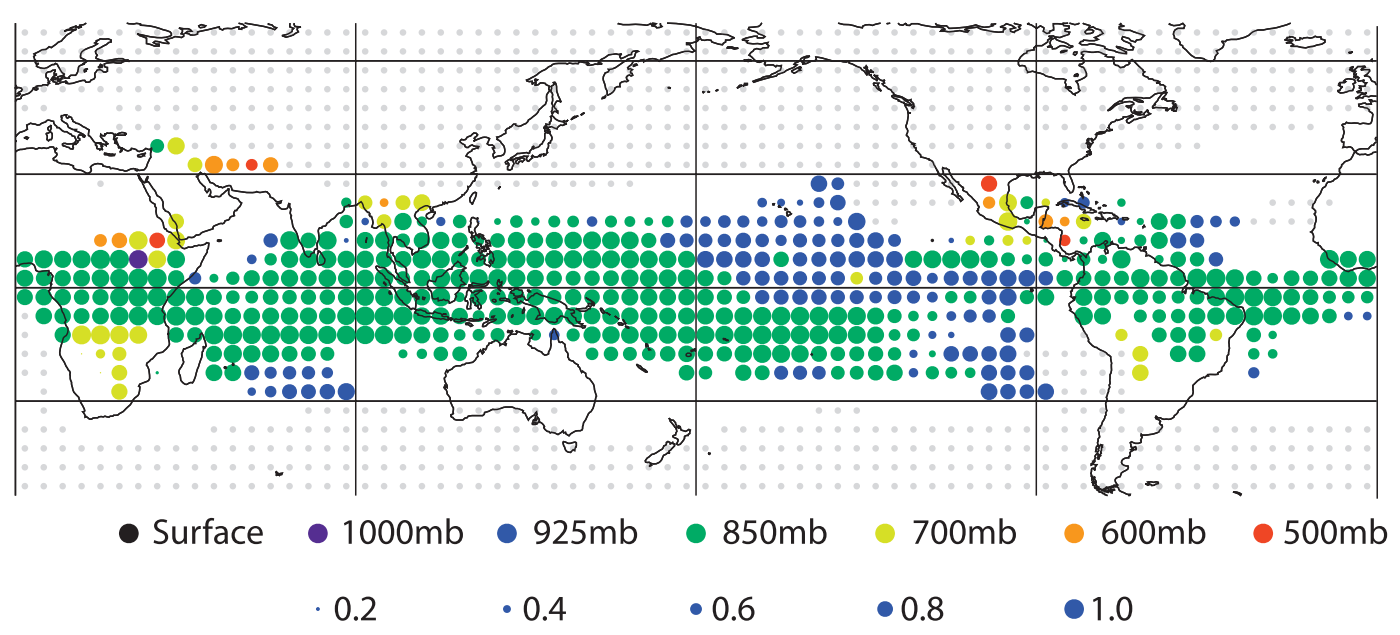

FIG. 2. Magnitude (radius) and level (color) of the highest correlation coefficient between CIN and DTTD at each grid point in (a) January, (b) April, (c) July, and (d) October. Gray dots indicate regions at which the ratio of the convective precipitation to the total precipitation is less than 0.7 .

convective parameters. In addition to the monthly average values of these characteristics, the amount of precipitation might also depend upon how much day-to-day variability is present about these monthly mean characteristics.

\section{b. Local and regional relationships between convective parameters and precipitation}

Several previous studies have investigated the relationships between the variability of precipitation and convective instability, and the results are not entirely compatible with each other. A significant role of CIN in regulating initiation of deep convection is found in the southern Amazon basin (Fu et al. 1999). Interannual variability of precipitation is tightly linked with that of precipitable water in the tropical Pacific (Zveryaev and Allan 2005). DeMott and Randall (2004) found little correlation between monthly anomalies of tropical rainfall and CAPE. Biasutti et al. (2004), using a model, found CAPE to modulate precipitation over the tropical Atlantic. CAPE is strongly positively correlated with precipitation over the Eastern Mediterranean (Eshel and Farrell 2001).

In the west Pacific, the variation of convective parameters associated with intraseasonal oscillations has been extensively studied. Convective breaks are typically triggered by dry midtropospheric air, which increases CIN, and the resulting suppression of convection allows CAPE to build up while CIN in turn gradually decreases (Sherwood 1999; Parsons et al. 2000; Agudelo et al. 
(c) Jul

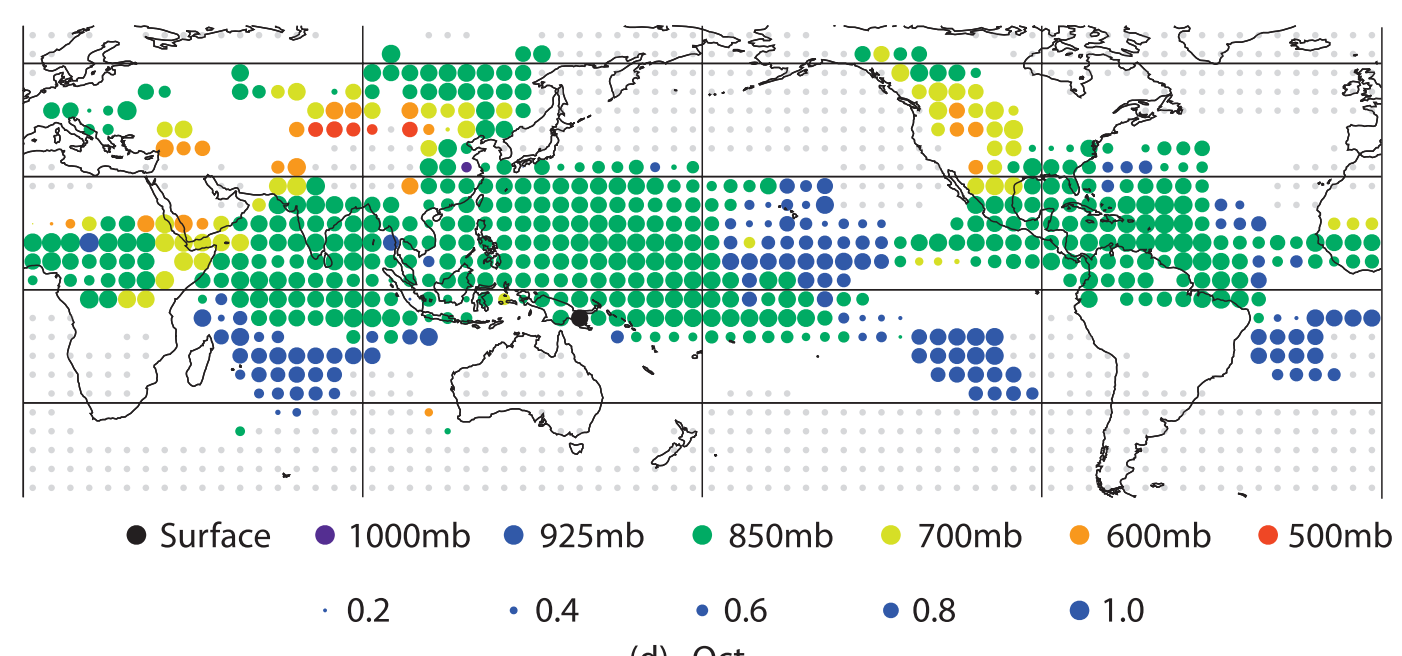

(d) Oct

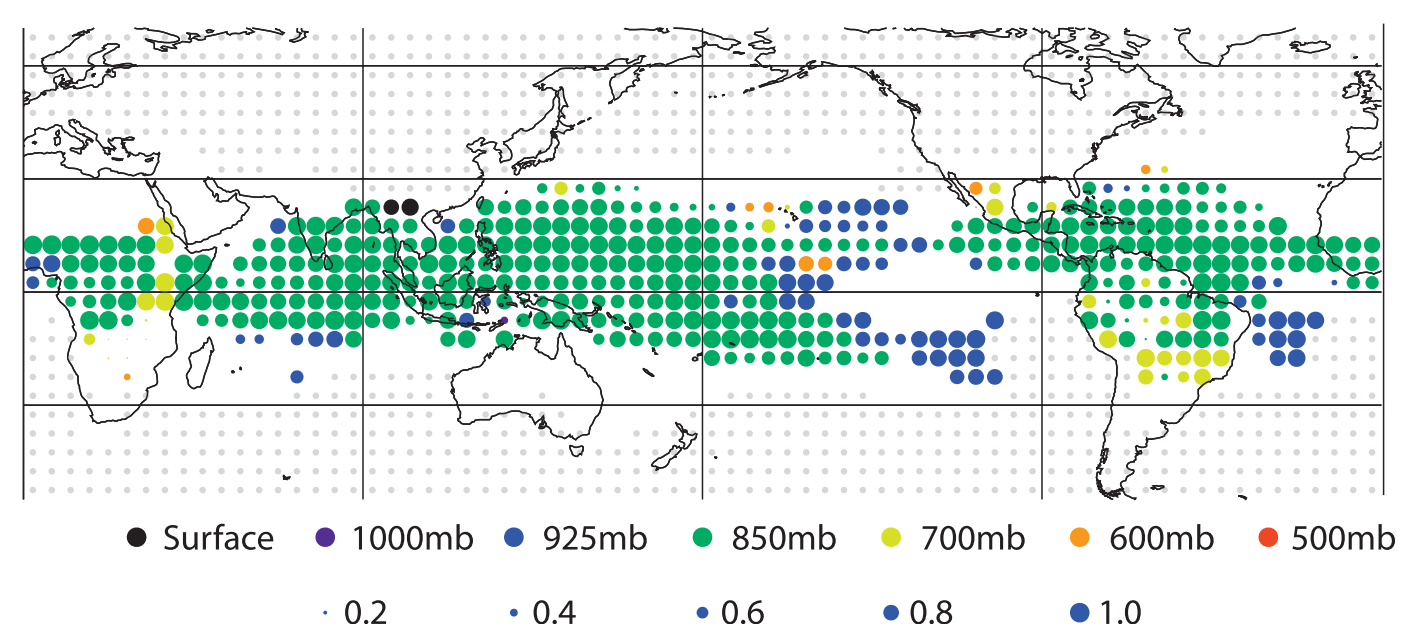

FIG. 2. (Continued)

2006). However, it is not clear how this evolution should be translated into a relationship between monthly mean precipitation and monthly mean convective parameters.

Additional insight into monthly time scales can be gained from studies of seasonal precipitation transitions. Over India, CAPE is present well before the onset of monsoon rains, but the rains do not begin until CIN becomes sufficiently small (Bhowmik et al. 2008). Similarly, the decrease of CIN appears to control the onset of monsoonal rains in West Africa (Sultan and Janicot 2003).

\section{c. Purpose and outline}

While the studies mentioned above have investigated the relationship between precipitation and convective instability locally or regionally, there are no previous studies that look at convective precipitation globally with respect to convective instability, and the individual local or regional studies use a variety of methods. The purpose of this study is to unify and extend previous research by investigating the interannual variability of precipitation and its connection to convective instability on monthly time scales across the entire globe. This study will quantify the significance of convective parameters such as CIN, PW, and CAPE for monthly precipitation variations. By examining how convective instability is associated with monthly precipitation over all regions where convective precipitation prevails, we will better be able to understand how precipitation processes are sensitive to location and season. A similar approach is useful for testing global climate models, as their ability to simulate long-term variations in precipitation amounts should depend on whether the simulated 


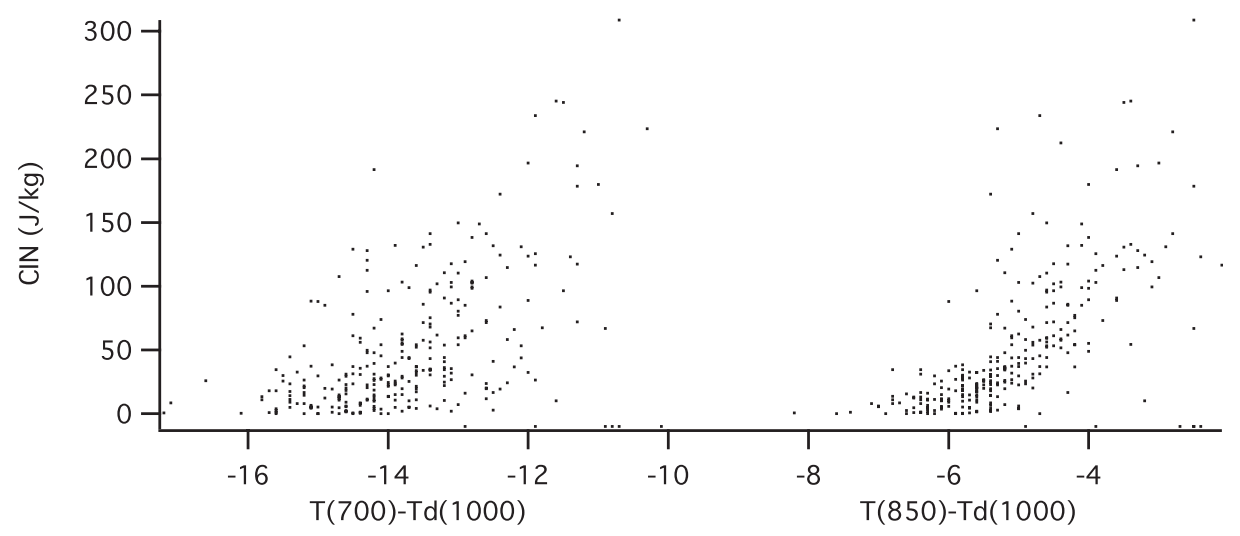

FIG. 3. Sample comparison of CIN values with DTTD computed using (left) $700 \mathrm{hPa}$ - and (right) $850-\mathrm{hPa}$ temperature, subtracted from 1000-hPa dewpoint. DTTD values are in kelvins. The points represent 0000 UTC soundings during 1980 in Singapore. Soundings with CIN undefined because of the absence of CAPE are represented as CIN $=-10 \mathrm{~J} \mathrm{~kg}^{-1}$.

precipitation is controlled by the correct large-scale environmental characteristics.

In principle, monthly variations in convection must be controlled directly by the thermodynamic and kinematic characteristics of the atmosphere during those monthsif there is a clear scale separation between the convection and its environment. Thus, one can say that environmental conditions cause variations in convection. By investigating correlations between convective parameters and precipitation, this study seeks aspects of the thermodynamic structure of the atmospheric environment that are strong candidates for exerting a controlling influence on convective precipitation in particular months and locations, and conversely to exclude other thermodynamic aspects that are not strongly correlated with precipitation and therefore must not exert a controlling influence. Determining whether a particular correlation represents a causal relationship between thermodynamic structure and precipitation is beyond the scope of this study.

The paper is organized as follows. Section 2 outlines the data and methods used in this study and discusses sources of error. Proxies of convective parameters are identified in section 3 . The study region is defined in this section. Section 4 investigates the characteristics of precipitation by examining relationships of convective parameters with precipitation. The underlying physics and implications for the results of this study and predictability of precipitation using convective parameters are discussed in section 5. The major results and conclusions of this study are summarized in section 6 .

\section{Data and methods}

\section{a. Observed and reanalysis precipitation}

To investigate the coupling of precipitation with convective parameters, two monthly precipitation datasets were used in this study. The first dataset is global precipitation from the Global Historical Climatology Network $(\mathrm{GHCN})$ gridded at $5^{\circ} \times 5^{\circ}($ Chen et al. 2002). This dataset contains monthly anomalies with respect to $1961-$ 90. The second dataset is the National Centers for Environmental Prediction-National Center for Atmospheric Research (NCEP-NCAR) reanalysis data (Kalnay et al. 1996) aggregated to $5^{\circ} \times 5^{\circ}$, whose precipitation is computed through model integration and is not based on precipitation observations. The time domain for this study covers the continuous 56-yr period from 1948 to 2003.

While GHCN is excellent in signal detection, accuracy, and longevity of record, it has poor coverage over oceanic areas since it is obtained from precipitation stations that are densely distributed over land. Conversely, the reanalysis precipitation is spatially complete but is computed from a model's data assimilation cycle rather than from direct observations. The reanalysis precipitation has been found to be highly correlated with observed precipitation over the midlatitude land and ocean in the Northern Hemisphere, the central Pacific, and Australia, but only weakly correlated in the western Pacific islands, central Africa, and northern South America (Janowiak et al. 1998; Trenberth and Guillemot 1998). Despite the low correlations over the regions described above, employing the reanalysis has the

TABLE 1. Surface pressure values and associated best proxy levels for calculation of DTTD, a proxy for CIN.

\begin{tabular}{cc}
\hline \hline Surface pressure $(\mathrm{hPa})$ & $\begin{array}{c}\text { Assumed best } \\
\text { proxy level }(\mathrm{hPa})\end{array}$ \\
\hline$<870$ & 600 \\
$870 \sim 980$ & 700 \\
$980 \sim 1013.25$ & 850 \\
$>1013.25$ & 925 \\
\hline
\end{tabular}


advantages of internal consistency between the nature of the controls and the precipitation as well as its excellent temporal and spatial extents. In fact, correlations may underestimate accuracy owing to the existence of random spatial noise on a gridpoint basis and removal of real spatial variations within a basin on a basin-averaged basis. Results using reanalysis and GHCN precipitation are compared in section $4 \mathrm{a}$.

Another convenient aspect of the reanalysis precipitation dataset is its distinction between convective and total precipitation. Convective parameters should directly influence monthly precipitation only where convection is the dominant mode of precipitation. Thus, this study focuses on the regions in which the ratio of mean monthly convective precipitation to mean monthly total precipitation in the reanalysis is greater than 0.7.

Figure 1 depicts the geographical distribution of this ratio: areas with values greater than 0.7 (hereafter, convection-preferred regions) are shaded. While the ratio shows strong seasonal variations over land, convectionpreferred regions include most of the tropics and subtropics in all seasons. They exclude some desert areas such as the Sahara and Gobi as well as the eastern Pacific and Atlantic subtropics where subtropical anticyclones prevail.

\section{b. Reanalysis convective parameters and relationship with convection}

The convective parameters studied are CIN, PW, and CAPE or their proxies. No attempt is made to distinguish between low-level and midlevel moisture. Vertical wind shear and variability of convective parameters within months are also ignored.

The reanalysis provides monthly mean variables such as temperature and dewpoint on 17 pressure levels and surface temperature and dewpoint. From these variables, various stability indices are calculated, as described in section 3 .

The physical mechanisms of precipitation controls in the reanalysis are intimately related to the convective parameterization in the reanalysis modeling system, which is a simplified Arakawa-Schubert scheme based on Grell (1993) (Kalnay et al. 1996). This scheme prescribes convection in terms of a cloud work function that depends upon cloud base buoyancy (and thus CIN) and differences between the moist static energy of a parcel and its environment (and thus CAPE and PW). Although the scheme assumes quasi equilibrium such that convection balances the destabilization produced by the large-scale environment, the stability characteristics of the environment are free to evolve on time scales larger than that of convective adjustment (Arakawa and Schubert 1974). Thus, reanalysis precipitation, although parameterized, should be sensitive to all three environmental characteristics being considered here.

\section{c. Methods}

Linear correlation analysis is performed between the precipitation datasets and the convective parameters. Because precipitation values are bounded by zero, they tend to have a lognormal distribution; therefore, they are usually transformed for linearity using the logarithm. However, the GHCN precipitation values are monthly anomalies, which permits negative values. Regional tests with reanalysis precipitation showed that correlation coefficients were not substantially affected by a lognormal transformation of the precipitation, so no such transformation is applied here.

In addition to the correlation analysis, we use linear regression analysis to determine the parameters most relevant to precipitation. The resulting Pearson correlation coefficient $r$ indicates the strength of a linear relationship between the two fields. Assuming independent, normally distributed data, 0.34 is roughly the $99 \%$ confidence limit for a nonzero correlation.

\section{d. Sources of error}

Sources of error in the relationship between convective parameters and precipitation include the following:

1) Only three numeric values (PW and proxies for CIN and CAPE) are used to represent the convective environment. This oversimplifies the environment and underestimates the extent of environmental control. While these three were selected because they are believed to be most fundamental, it is possible that in certain locations other environmental parameters (that may or may not covary with the chosen three) may have greater importance. Since PW is dominated by lower-troposphere humidity, the middle- and uppertropospheric relative humidity would be a possible separate variable to consider, but for major inconsistencies in reanalysis humidity fields in the middle and upper troposphere (Huang et al. 2005).

2) Random errors in the reanalysis of temperature and moisture or in the GHCN precipitation observations, or undersampling of precipitation within grid boxes in the GHCN precipitation observations, would weaken the correlations between convective parameters and GHCN precipitation. The comparison of reanalysis thermodynamics and precipitation has the advantage of eliminating sampling error.

3) Systematic biases in the reanalysis of temperature and moisture could lead to an incorrect relationship between convective parameters and reanalysis precipitation but would not affect the correlations 
(a) Jan

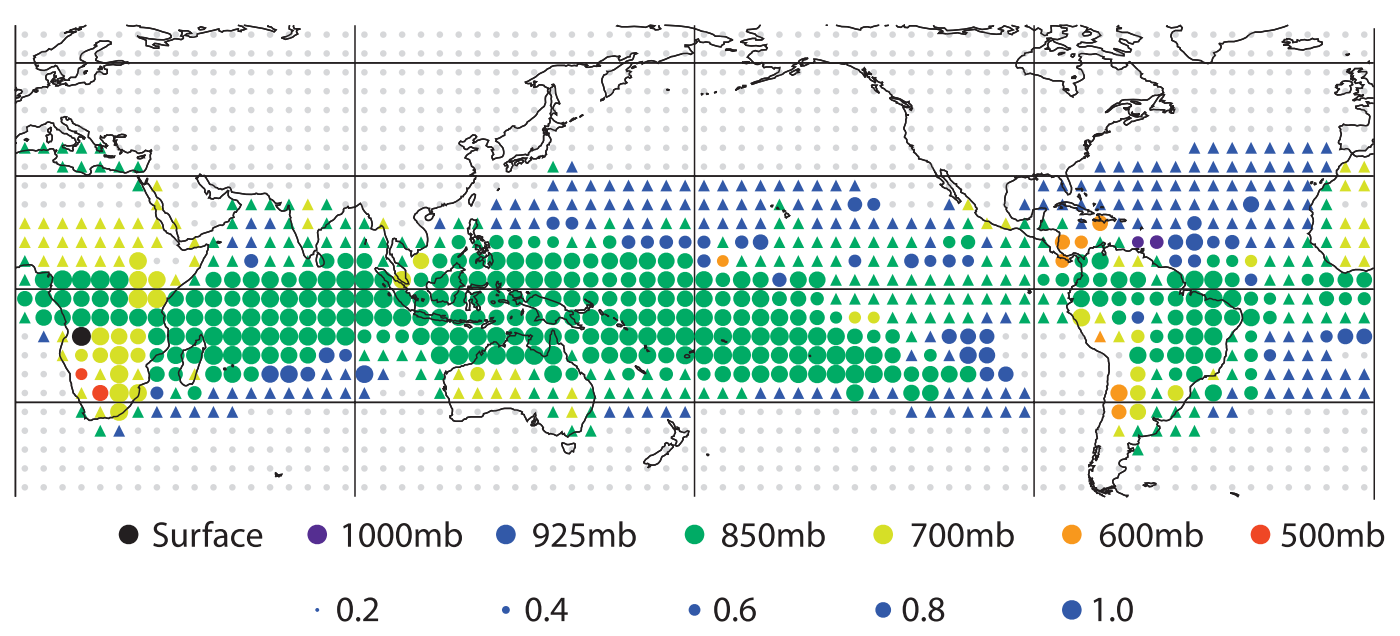

(b) Apr

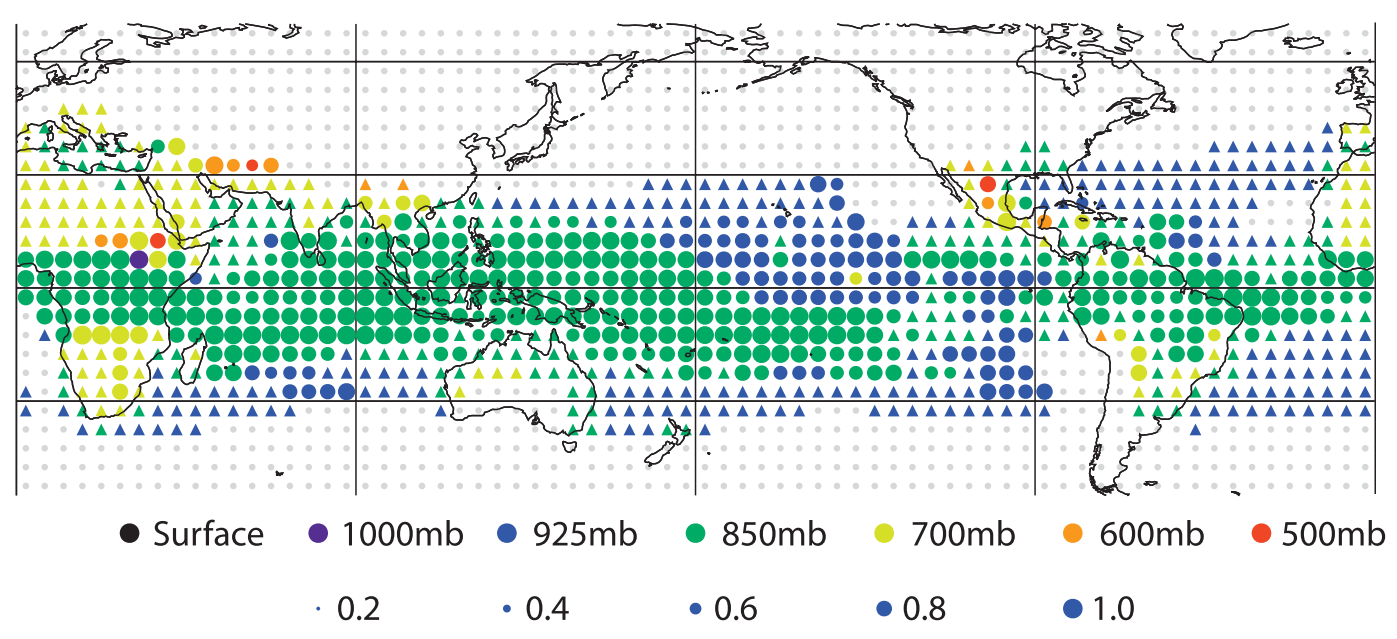

FIG. 4. Optimized best proxy levels based on Table 1 (triangles) and observations (circles) in (a) January, (b) April, (c) July, and (d) October.

between convective parameters and GHCN precipitation. For example, Trenberth and Guillemot (1998) found discrepancies in the reanalysis moisture budget centered around certain island rawinsonde sites. Differences between correlations in data-rich and data-poor areas may be evidence of such a bias. Also, Li and Chen (2005) found unrealistic seasonal variations of precipitable water in the NCEP-NCAR reanalysis over the Asian and Australian monsoon regions.

4) Time-varying biases in the reanalysis dataset would detrimentally affect all results. The reanalysis has a generally reasonable representation of diagnostic variables such as evaporation, soil moisture, and sen- sible and latent heat fluxes as well as instantaneous variables like temperature, specific humidity, height, and winds on a monthly time scale (Roads and Betts 2000), but exceptions exist in certain locations and fields. Zveryaev and Chu (2003) found multidecadal variations in precipitable water from region to region that may have been related to the introduction of satellite data in 1979 but are not easily separated from natural variations.

5) As noted above, the reanalysis precipitation is not based directly on observations but is a consequence of model integration. Without corroborating evidence, correlations between reanalysis precipitation and reanalysis convective parameters should be 
(c) Jul
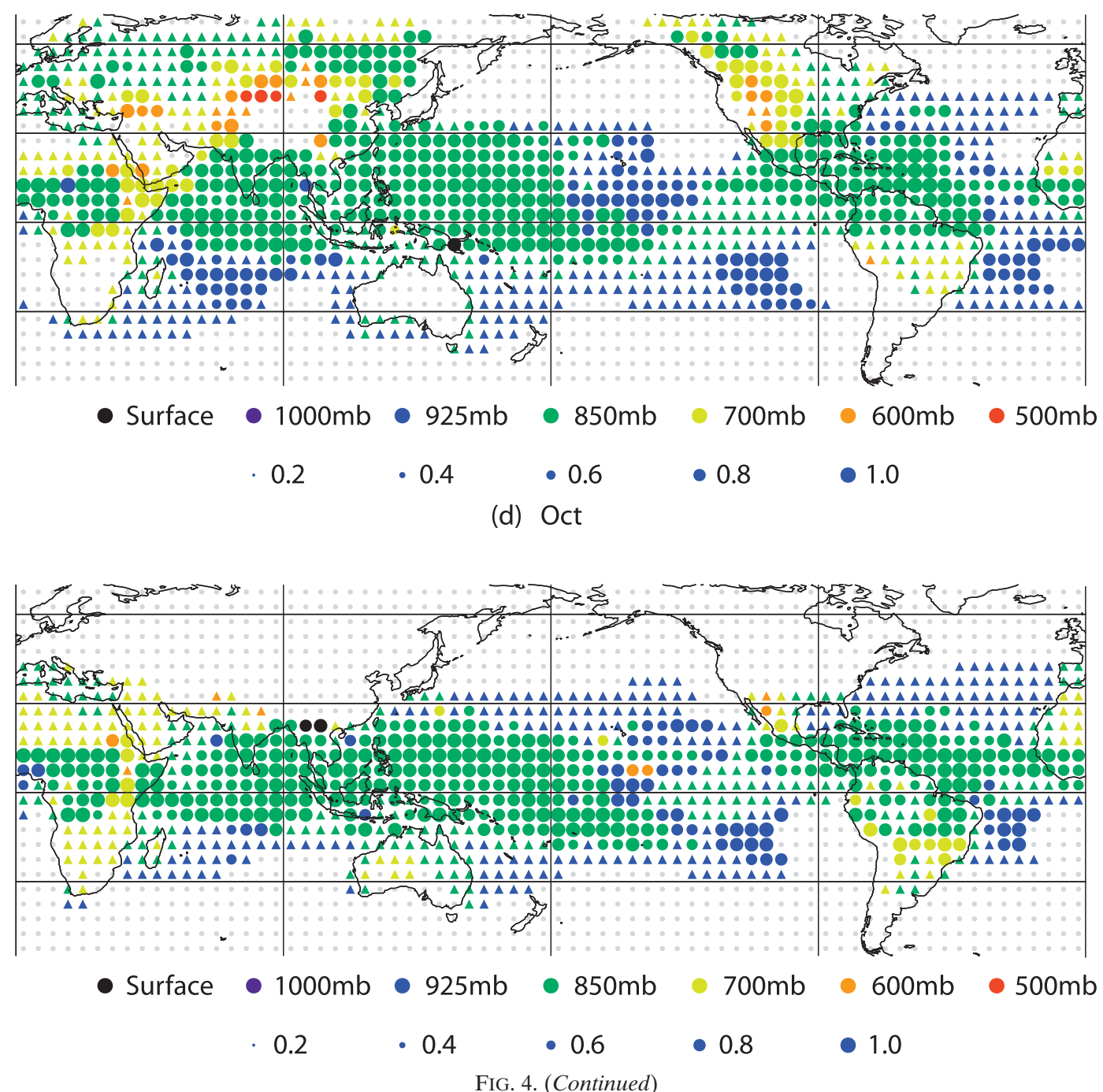

interpreted as diagnostic of the model behavior rather than of the behavior of the real atmosphere. The results are more likely to represent atmospheric behavior where the results from reanalysis precipitation and GHCN precipitation agree and are in similar climatological settings around the globe.

\section{Proxies of CIN and CAPE}

CIN and CAPE are the most direct measures of convective instability and inhibition to convection. However, on days when convective instability is absent, both CAPE and CIN are undefined. In areas only marginally supportive of convection, even monthly means might occasionally have undefined CAPE and CIN. Conversely,
CIN is uniformly zero whenever convective inhibition is absent. These properties make CAPE and CIN unsuitable for correlation analysis. Needed are indices that vary continuously and are always defined. In this section, proxies for CIN and CAPE will be tested and determined.

\section{a. $C A P E$}

Some controversy exists over the proper way of computing CAPE in the tropics (Williams and Renno 1993; Thompkins and Craig 1998; Frueh and Wirth 2007), owing to potential influences of water loading and freezing. Fortunately for our purposes, these factors affect the absolute magnitude of CAPE, but interannual variations in monthly mean CAPE should be insensitive to 
(a) JAN

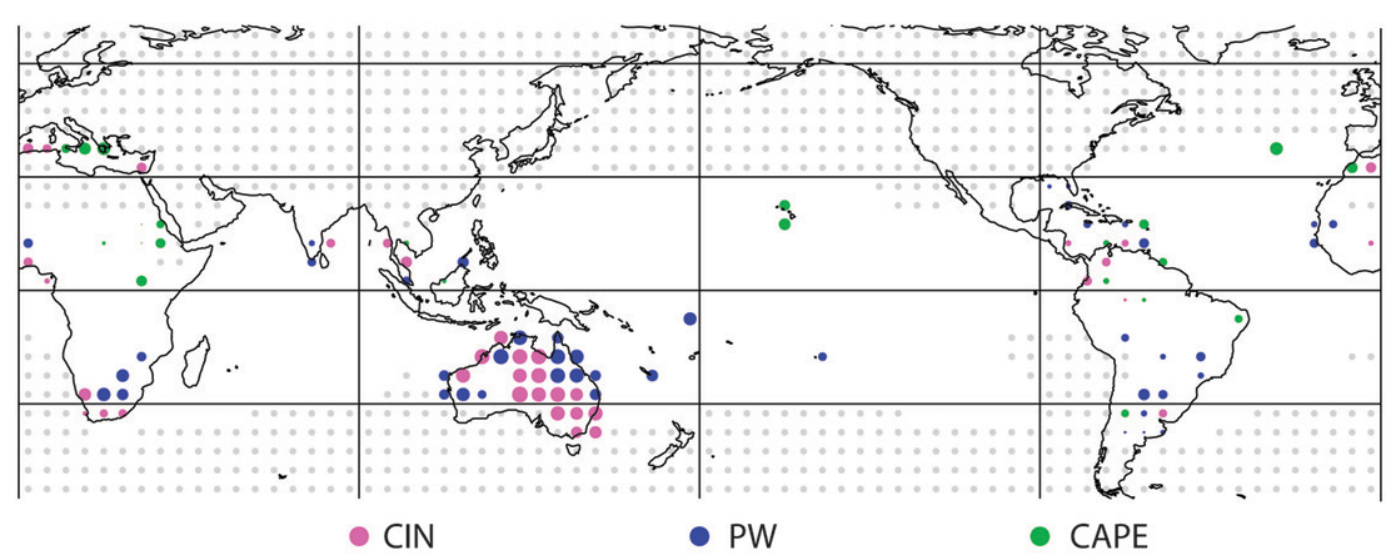

(b) JUL

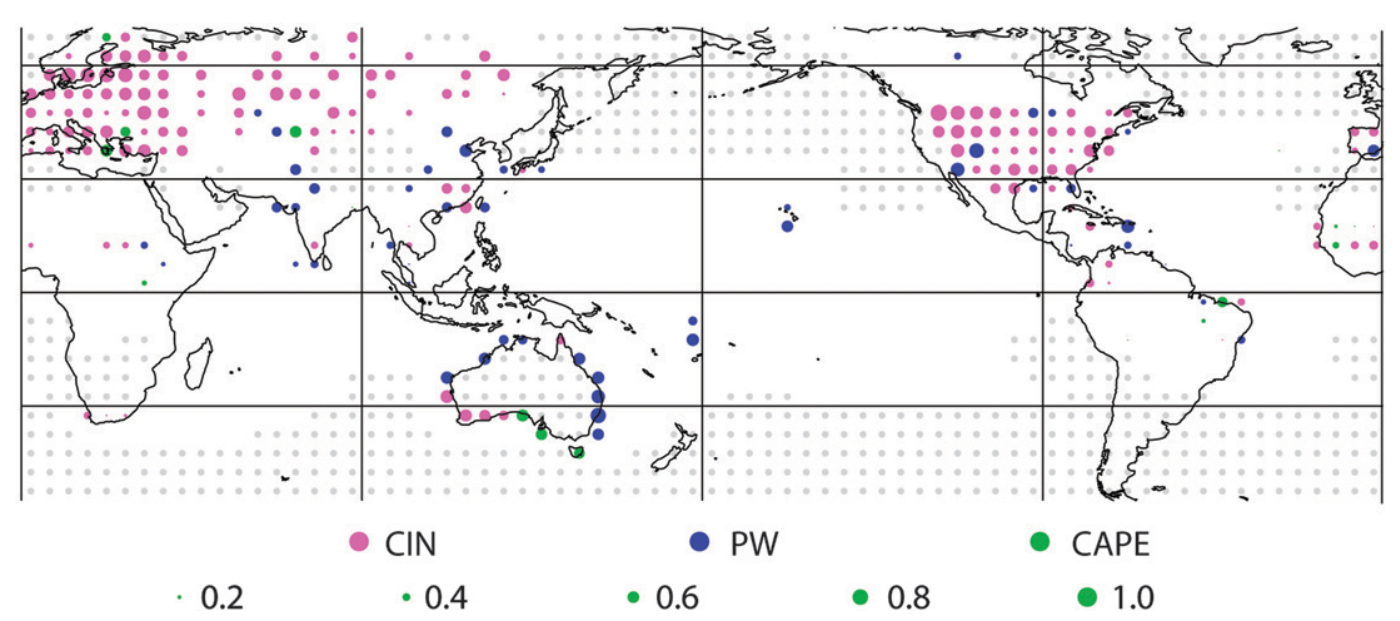

FIG. 5. Parameter (color) and magnitude (radius) of the highest correlation using GHCN precipitation in (a) January and (b) July. CIN (pink), PW (blue), and CAPE (green). Correlations whose signs are consistent with convective instability theory are represented as circles, and the opposite relationships are represented as triangles.

the specific algorithm used as long as it is applied consistently. Also, monthly averaging should smooth out random details in the vertical stability profile, allowing buoyancy at a representative level to serve as a proxy for the integrated buoyancy CAPE.

The lifted index (LI) is the temperature difference between an air parcel lifted pseudoadiabatically and the temperature of the environment at a particular pressure in the midtroposphere, $500 \mathrm{hPa}$. When the value is positive (negative), the atmosphere is stable (unstable). Therefore, LI is generally expected to be negatively correlated with CAPE. We find that the correlation between LI and CAPE at each grid point for which CAPE is defined for all 56 years is generally between -0.8 and -1.0 , confirming that LI can be used as a proxy of CAPE.

\section{b. $C I N$}

A proxy analogous to LI would be useful for CIN, but we are not aware that any have been proposed. In principle, CIN should depend on the temperature and dewpoint at the surface [ $T(s)$ and $T_{d}(s)$, respectively] and the virtual temperature [here, for simplicity, temperature $T($ inv)] at some level just above the mixed layer or within a capping or trade wind inversion.

An exploration of the relationships between these three variables and CIN was performed for summertime monthly-mean conditions in Texas, taking $700 \mathrm{hPa}$ as a reasonable level for $T(\mathrm{inv})$. An excellent correlation (0.98) was found between CIN and $T$ (inv) $-T_{d}(s)$. Physically, $T_{d}(s)$ is strongly correlated with the moist pseudoadiabat along which a surface parcel will ascend, 
and $700 \mathrm{hPa}$ is typically just above the planetary boundary layer (PBL) in Texas in summertime, so T(inv) $T_{d}(s)$ correlates with the lifted index of a parcel measured close to the capping inversion. Details of this analysis will be reported in Myoung and Nielsen-Gammon (2010, manuscript submitted to J. Climate).

The example of Texas suggests that the difference between the temperature in the lower troposphere above the PBL and surface dewpoint may be a good proxy for CIN. Since the height of the PBL varies by location, the proper pressure level in general is unknown. Therefore, we seek to find the lower-troposphere level at which the temperature minus surface dewpoint correlates most strongly with CIN at each grid point.

Using the monthly mean reanalysis data, surface dewpoint is subtracted from temperatures at various levels (surface, 1000, 925, 850, 700, 600, and $500 \mathrm{hPa)}$ ), and the correlation coefficients between these differences and CIN were calculated at each grid point. This analysis was performed only at the grid points where CIN was defined in at least 20 out of 56 years for a given month.

Figure 2 illustrates with colors the lower-tropospheric level for which the correlation coefficient $r$ between $T$ (inv) $-T_{d}(s)$ and CIN is highest at each grid point, and the value of $r$ is given by the size of the color-coded circle. Low values of $r$ are often found in grid points at the margin of the convection-preferred regions, which may be due to a lack of samples. The pressure levels of 925 and $850 \mathrm{hPa}$ are generally the best levels for $T$ (inv) over the ocean. While $850 \mathrm{hPa}$ produces the highest correlations over the western Pacific, central Indian Ocean, Caribbean, and western Atlantic, $925 \mathrm{hPa}$ is the dominant level over the northeastern and southeastern Pacific, south Indian Ocean, and southeastern Atlantic. Grid points over land are generally associated with pressure levels at least as high in altitude as $850 \mathrm{hPa}$. These patterns are consistent in all months with slight seasonal variations in the transition zones.

In Fig. 2, three noteworthy features are 1) $r$ values exceeding 0.6 are nearly ubiquitous over the analysis region; 2) only rarely is the surface the best level for $T$ (inv), which would represent a correlation between surface dewpoint depression and CIN; and 3) the best level is dependent of location. The second is consistent with the results in Texas, implying that low-tropospheric temperature is more significant to the variation of CIN than temperature at the surface. Overall, the generally high correlations indicate that there is a specific pressure level at which the temperature minus surface dewpoint is highly correlated with CIN at each grid point, suggesting that the difference between this temperature and the surface dewpoint (DTTD) is a good proxy for CIN.
Figure 3 compares the relationship between CIN and two possible CIN proxies for a sample year at Singapore, using daily rawinsonde observations. Undefined values of CIN are plotted as zeroes. This is a more stringent test of the CIN proxy than the reanalysis comparisons above because the potential correlation between CIN and its proxy is negatively affected by small-scale details in vertical structure that would be smoothed out in monthly, grid-square-averaged information.

Even at daily time resolution, the correlation between CIN and $T_{850}-T_{d}(s)$ is 0.73 . This excludes seven sounding days when CIN was undefined because CAPE was zero, most of which occurred with $T_{850}-T_{d}(s)>$ $-3^{\circ} \mathrm{C}$ (in Fig. 3, these cases are indicated with CIN values of $-10 \mathrm{~J} \mathrm{~kg}^{-1}$ ). The proxy is able to represent the full range of stability conditions, while CIN is not. In addition, it can be seen that CIN has a highly skewed nonGaussian distribution, while the proxy is much closer to normally distributed. For both reasons, the CIN proxy is more appropriate than CIN itself for the present analysis. The finding in Fig. 2 that $T_{850}-T_{d}(s)$ is more tightly coupled to CIN at this location than $T_{700}-T_{d}(s)$ is confirmed here with sounding data, as the scatter of points is much broader and the correlation is lower for $T_{700}-T_{d}(s)$.

At grid points for which CIN is defined so infrequently that a correlation analysis would be unreliable, it is necessary to specify the level for computing $T$ (inv). To estimate the best proxy level over those grid points, we are interested in the physical factor(s) that determine this level. The differences in the best proxy level not only between ocean and land, but also within ocean or land areas, seem to be closely associated with surface pressure patterns. For example, within the Pacific, while $850 \mathrm{hPa}$ is the best proxy level in the western Pacific, the 925-hPa level dominates the northeastern and southeastern Pacific where subtropical highs and associated subsidence prevail. Over land, high terrain corresponds to a higher altitude for the top of the PBL, and thus a higher best proxy level. In general, over both land and oceans, the higher the surface pressure, the higher the pressure value of the best proxy level.

Based on statistical analysis of the relationship between surface pressure and the best proxy level, Table 1 shows the proxy levels to be used at those grid points where an insufficient number $(<20)$ of years of CIN data were available to calculate the best proxy level directly.

Figure 4 depicts observed (circle) and assumed (triangle) best proxy levels. The optimized levels are in good spatial agreement with the observed levels. For example, assumed best proxy levels of $925 \mathrm{hPa}$ are adjacent to observed best proxy levels of $925 \mathrm{hPa}$ over the southern Indian Ocean, North Pacific, southeastern Pacific, and North and South Atlantic. Over land, grid points with an 
(a) Highest in JAN

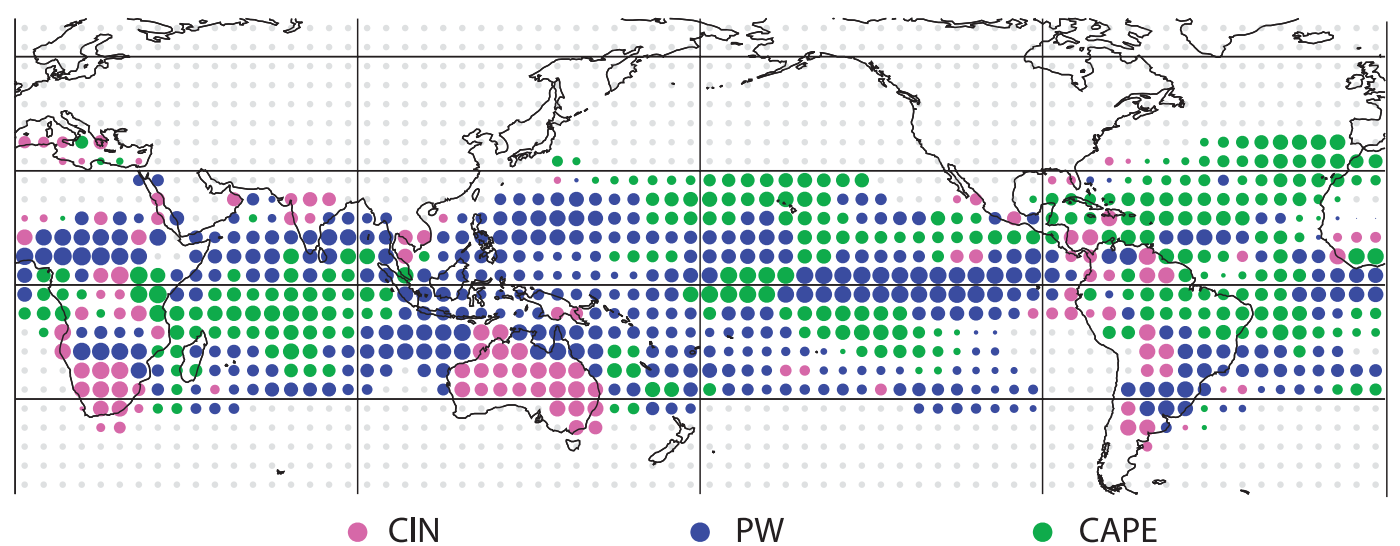

Middle

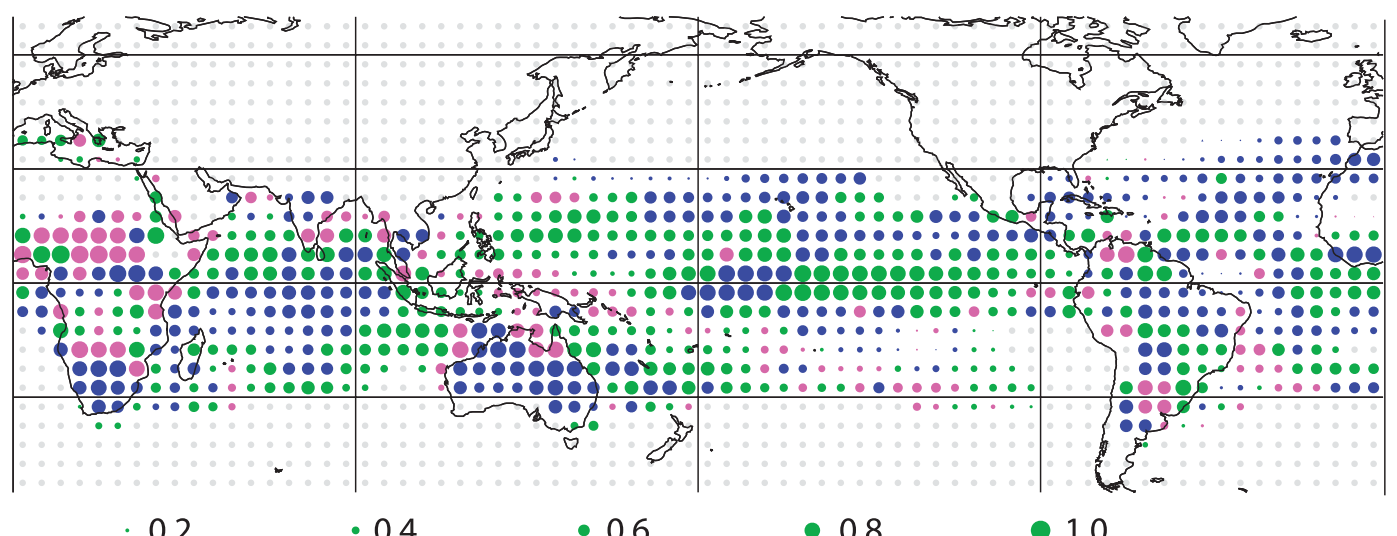

Lowest

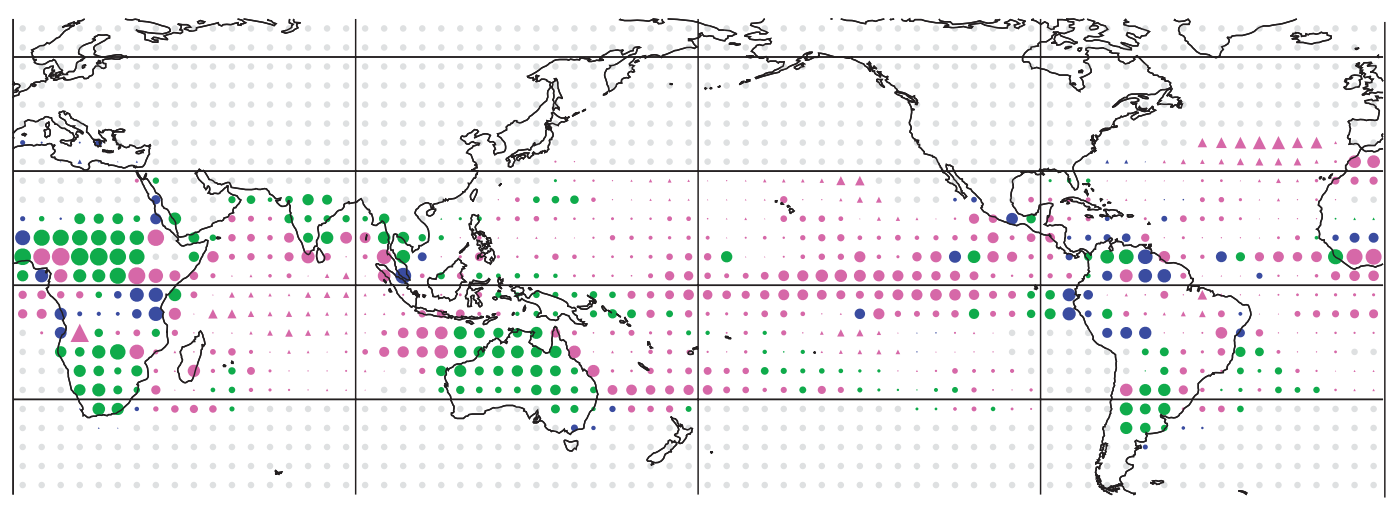

FIG. 6. Parameters (color) and magnitudes (radius) of the highest, middle, and lowest correlations using reanalysis in (a) January, (b) April, (c) July, and (d) October. CIN (pink), PW (blue), and CAPE (green). Correlations whose signs are consistent with convective instability theory (circles) and the opposite relationships (triangles) are represented.

assumed best proxy level of $600 \mathrm{hPa}$ are near observed best proxy levels of $600 \mathrm{hPa}$ over the Rocky Mountains and the periphery of the Tibetan Plateau in July (Fig. 4c). These features indicate that the estimation of the best proxy level based on the surface pressure is successful and that DTTD, the difference between the temperature at the best proxy level indicated in Fig. 4 and surface dewpoint at a given grid point, can be used as a good proxy of CIN. 
(b) Highest in Apr

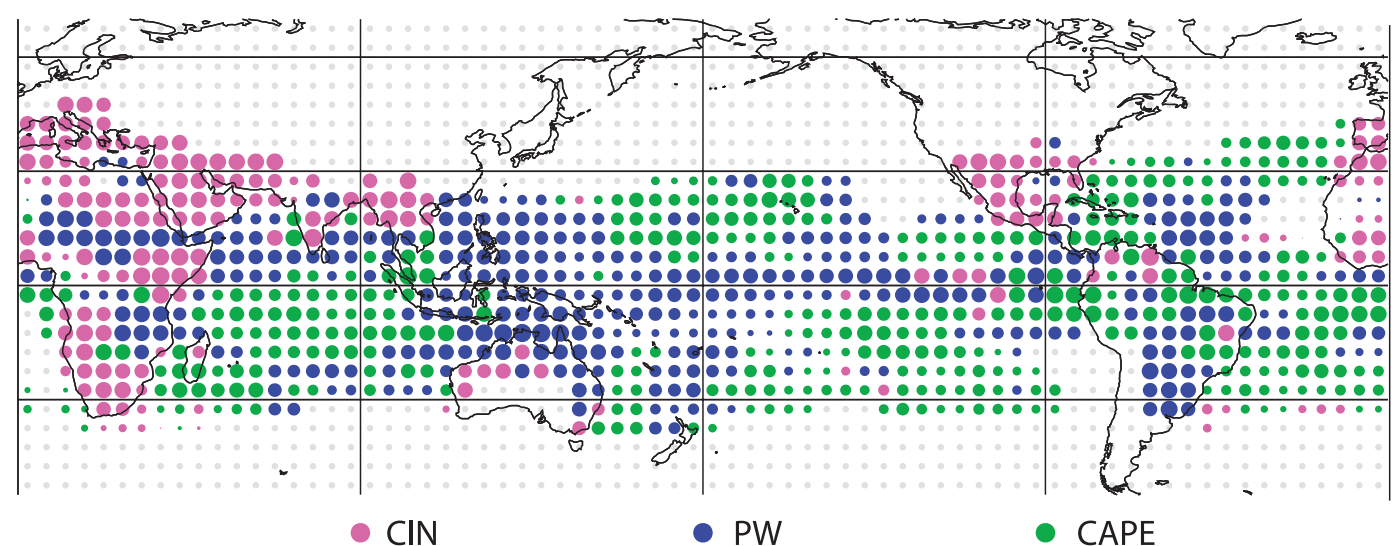

Middle

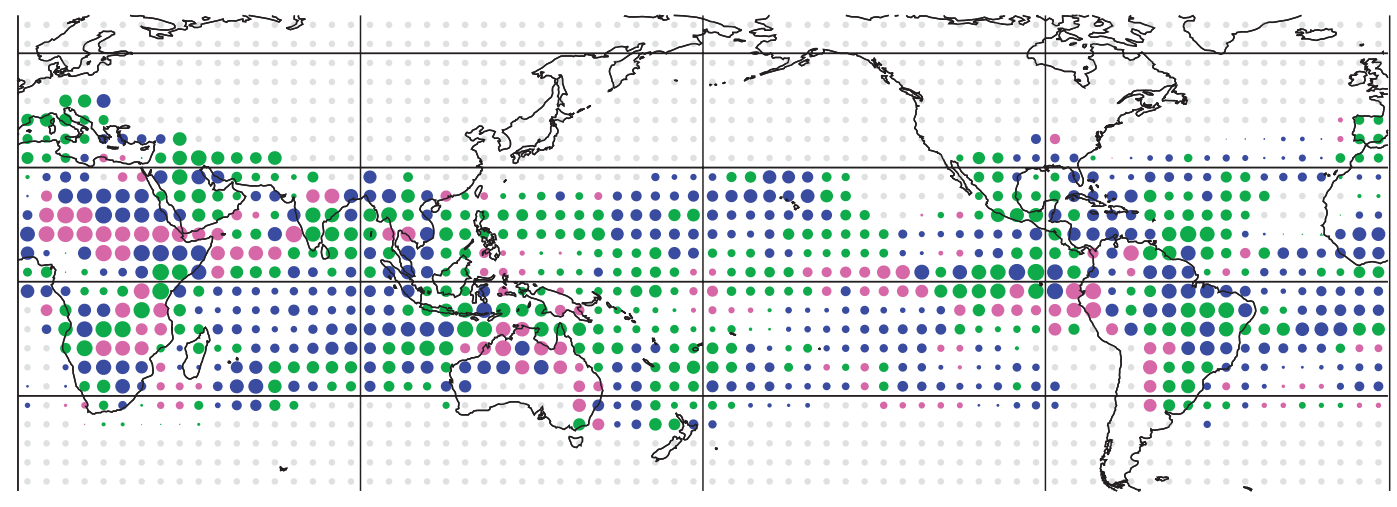

$\begin{array}{lllll}0.2 & \bullet .4 & \bullet & 0.6 & \bullet\end{array}$

Lowest

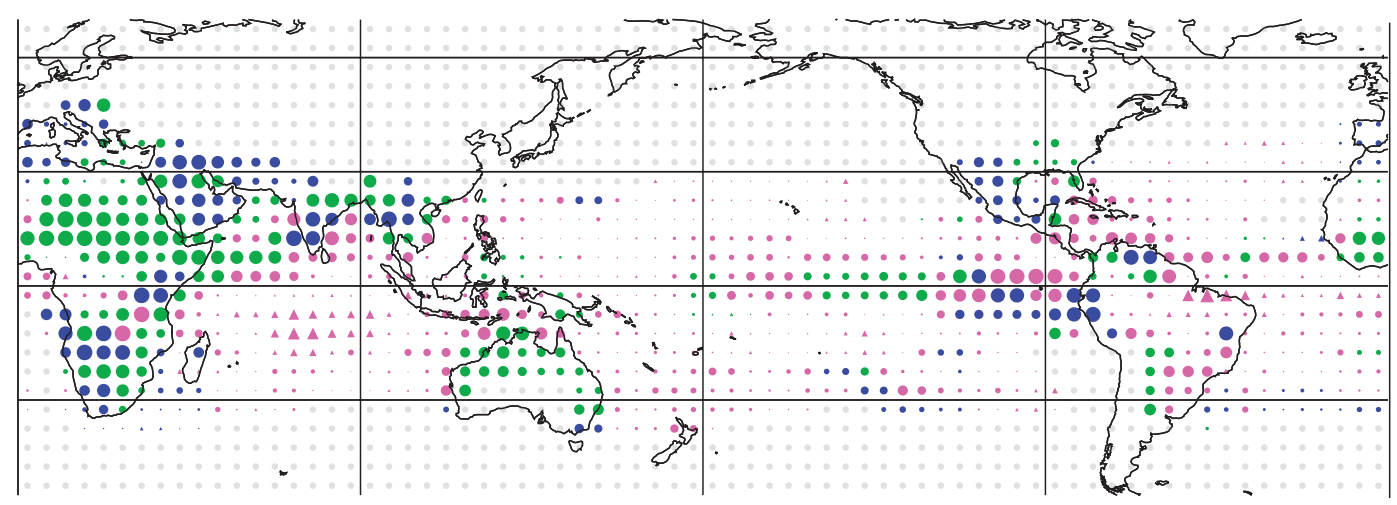

FIG. 6. (Continued)

\section{Most significant parameter for precipitation}

a. Comparison of GHCN with reanalysis precipitation

In this subsection, the results of the correlation analysis of the convective parameters with GHCN and pre- cipitation of the reanalysis are shown. Although we continue to refer to the physical quantities CIN and CAPE, the difference between temperature in the lower troposphere and surface dewpoint, DTTD, and the lifted index, LI, were used as proxies of CIN and CAPE, respectively. 
(c) Highest in JUL

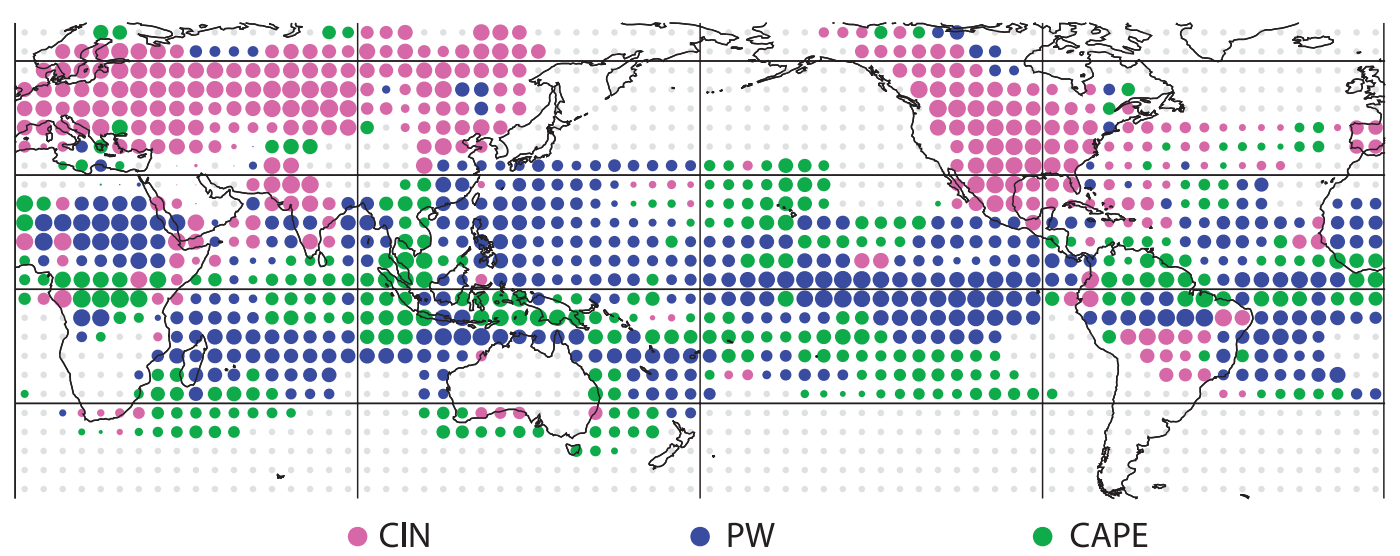

Middle

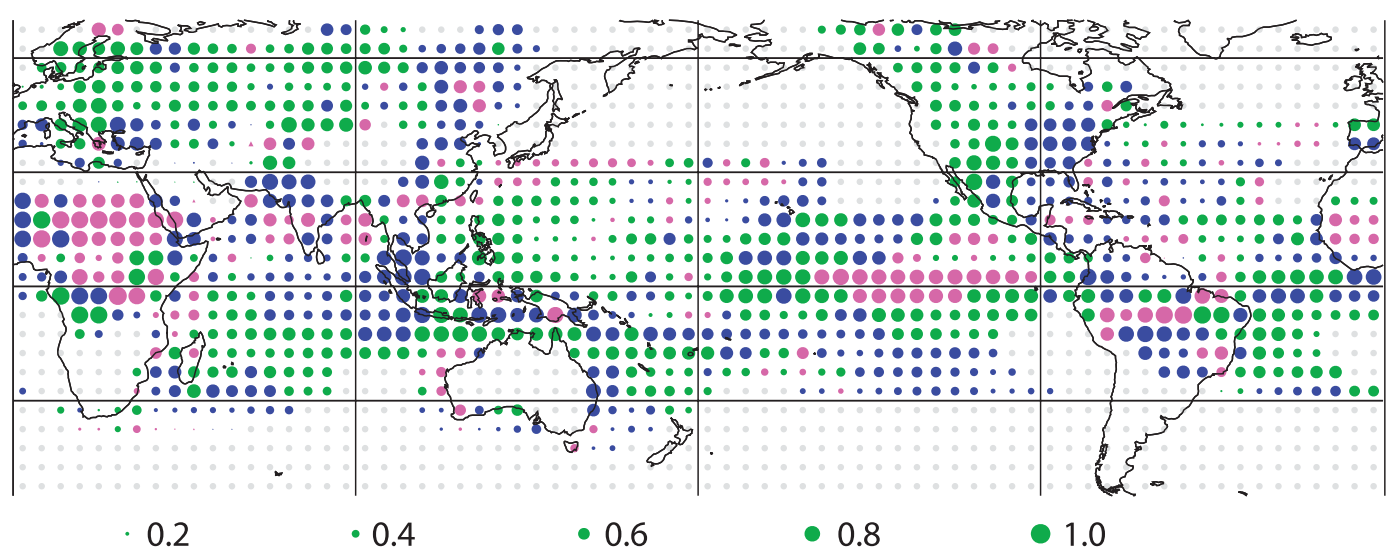

Lowest

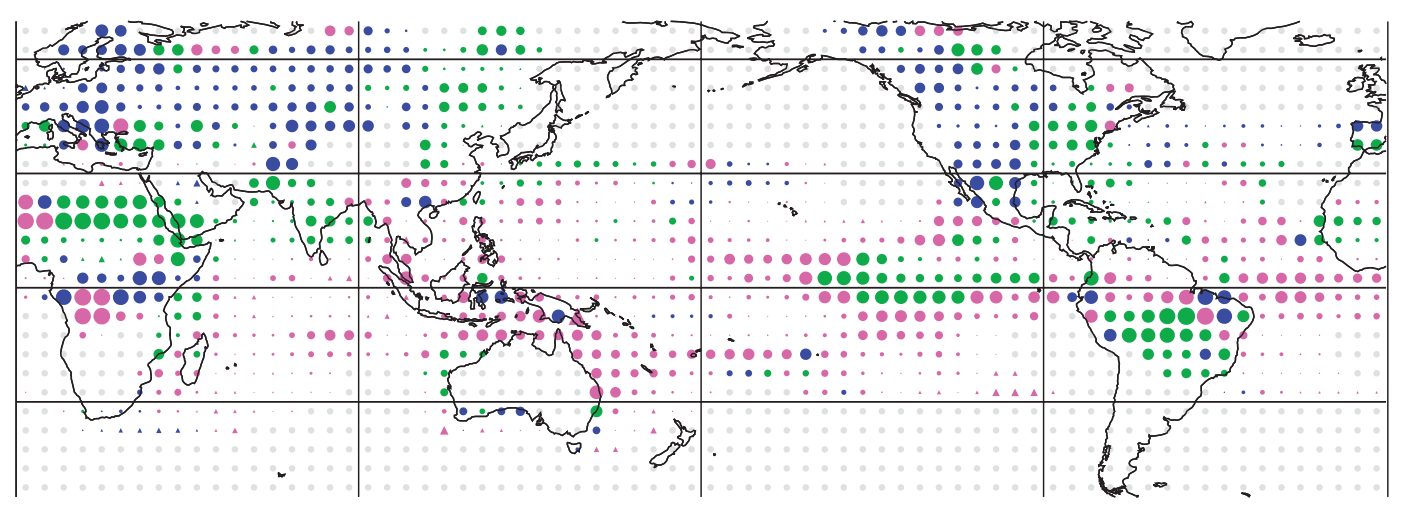

FIG. 6. (Continued)

Figure 5 identifies those parameters with the highest correlations with GHCN in January and July over the convection-preferred regions, while the top panels of Figs. $6 \mathrm{a}$ and $6 \mathrm{c}$ do the same for reanalysis precipitation. Correlations are only plotted if data are available for all
56 years, so GHCN correlations are rather sparse. The identity of the convective parameter with the largest $r$ (CIN, PW, or CAPE) is indicated by the dot color (pink, blue, and green, respectively), and the $r$ value is indicated by the radius of the dot. According to convective 
(d) Highest in OCT

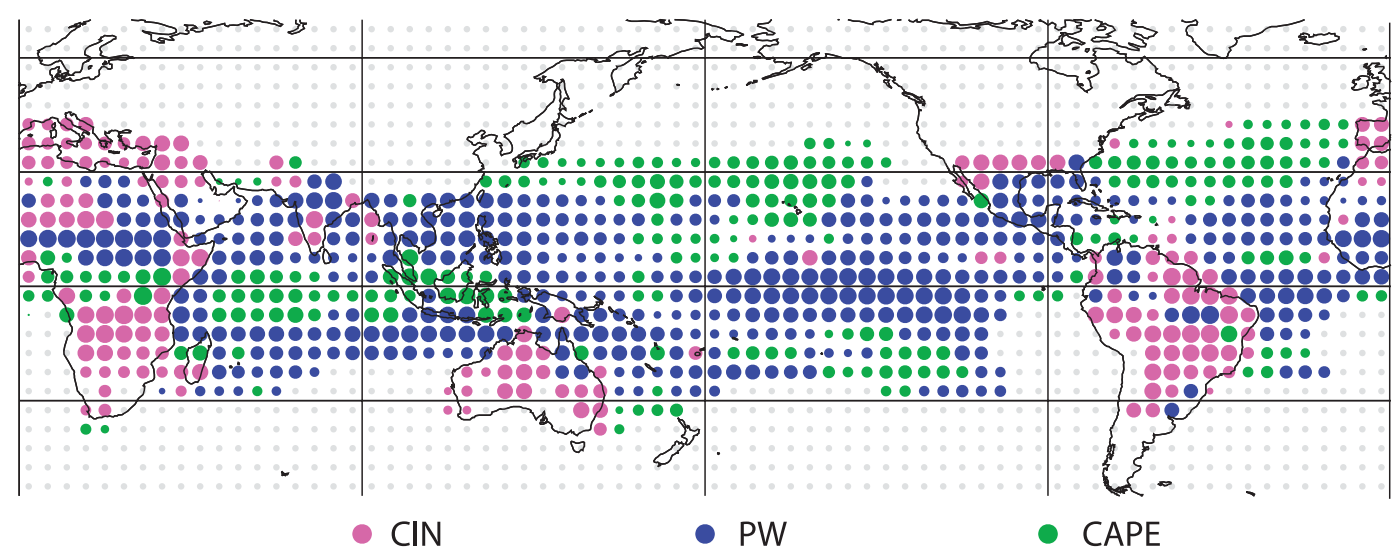

Middle

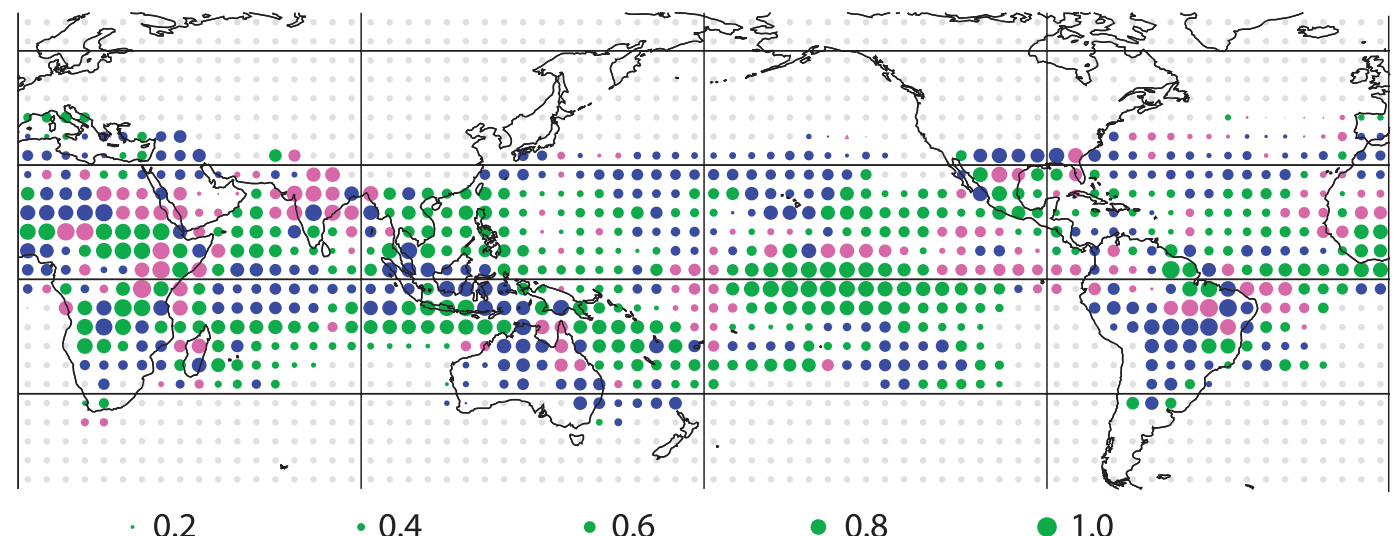

Lowest

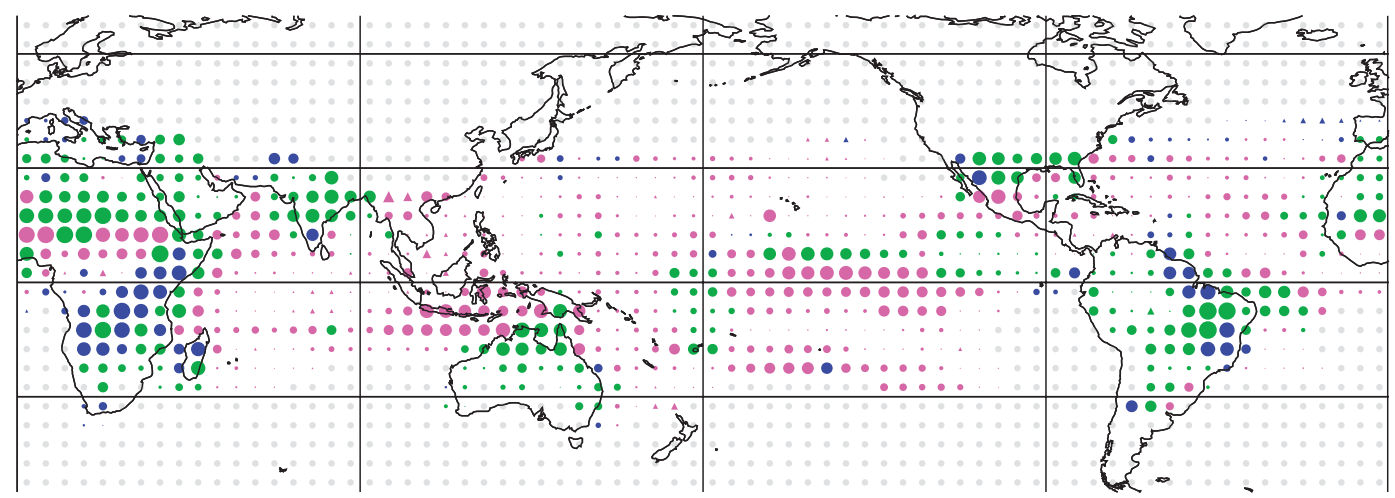

FIG. 6. (Continued)

instability theory, low CIN, high PW, and high CAPE are likely to increase the chances and amounts of precipitation, which would result in negative, positive, and positive correlations of precipitation with $\mathrm{CIN}, \mathrm{PW}$, and CAPE, respectively (negative with respect to the CAPE proxy, LI). Correlations whose signs are consistent with expectations are represented as circles in this and future figures, and the opposite relationships (positive for CIN, negative for PW, and negative for CAPE) are represented as triangles.

In January (Figs. 5a and 6a), the correlations generally agree. In Australia, agreement is excellent for both the 
best parameter and correlation magnitude, if allowance is made for minor spatial differences in the patterns. Similarly good agreement is found at islands in the Pacific and Atlantic Oceans and near the Mediterranean Sea. In central Africa and the Caribbean, the agreement is poor. In South Africa, South Asia, and South and Central America, the proper parameter is often identified, but reanalysis correlations are higher than observed correlations.

In July (Figs. 5b and 6c), both GHCN and reanalysis precipitation are in excellent agreement over North America, Europe, and Siberia. The best parameter is consistently identified in Europe, Asia, and North America, except for some points in the United States, while correlations are higher with the reanalysis precipitation. The agreement is fair to poor in Central Africa, South Asia, eastern Australia, and much of South America.

The agreement between the correlations of GHCN and reanalysis indicates that the relationship between the convective parameters and reanalysis precipitation is reliable over most land areas except for the tropical continents, and is at least partially consistent with observed precipitation over the oceans. Note that the reanalysis precipitation is solely model dependent, because no precipitation observation datasets are assimilated into the reanalysis system. The $r$ values with reanalysis precipitation are slightly higher than with GHCN precipitation, as expected since both reanalysis precipitation and reanalysis convective indices are required to be internally consistent and representative of gridpoint-mean conditions. Thus, we now proceed to a global statistical analysis of precipitation and convective indices using reanalysis precipitation values, recognizing that we are diagnosing numerical model behavior and comparing with previous observational studies.

\section{b. Correlation of the convective parameters with reanalysis}

The parameters with the highest, middle, and lowest correlation with reanalysis precipitation at each grid point are shown in Fig. 6. The presence of circles in most regions in Fig. 6 indicate that couplings of precipitation to the convective parameters or their proxies bear the expected sign, while the opposite relationships are found at several grid points with respect to the least strongly correlated convective parameter.

In January (Fig. 6a), PW or CAPE are most tightly coupled with precipitation over the oceans while the correlation with CIN is weaker. Within the oceanic areas, $\mathrm{PW}$ is dominant over the western tropical Pacific and CAPE is dominant over the central Indian Ocean and the Atlantic. The patterns over the oceans are not closely related to sea surface temperature; at larger distances from the equator where sea surface temperatures are cooler, many examples of either PW or CAPE being most strongly coupled can be found.

The importance of CAPE over the tropical Atlantic in January, and to a lesser extent in other seasons, is consistent with Biasutti et al. (2004); conversely, while CAPE is important over the Eastern Mediterranean, in agreement with the findings of Eshel and Farrell (2001), CIN is found to be even more important. Employing a time series of seasonal anomalies, Zveryaev and Allan (2005) also found a high correlation of precipitable water with observed precipitation in the tropical Pacific and moderate correlations in central Africa and South America in January. Precipitation is most strongly coupled with CIN over southern Africa and Australia and some parts of South America.

An analogous picture is manifest for April (Fig. 6b). Some major seasonal differences are shown over land in the Northern Hemisphere. In particular, CIN becomes dominant in northern Africa, southern Europe, western Asia, and southern North America. The high correlation with CIN over India is consistent with Bhowmik et al. (2008).

In July (Fig. 6c), the CIN correlation is pronounced over most of the continents in the Northern Hemisphere. While PW and CAPE are still dominant over the oceans, the pattern is different from that in January: PW, instead of CAPE, is most strongly coupled in the southwestern Indian Ocean and CAPE is less tightly coupled with precipitation in the Atlantic. The transition in West Africa from high CIN correlations in April to high PW correlations in July is consistent with the hypothesis of Sultan and Janicot (2003) that CIN controlled the onset of the monsoon, but after monsoon onset moisture transport became the key.

The pattern in October (Fig. 6d) is similar to that in April except that CIN is dominant in South America and CAPE (PW) prevails over the northern (central) Atlantic.

In all seasons when convection is the dominant mode of precipitation, precipitation and CIN are strongly coupled over most of the continental regions such as Europe, central and northern Asia, North America, and Australia. In contrast, CIN is least tightly correlated with precipitation over oceanic areas. This contrast is more clearly represented in Fig. 7, which shows histograms of the correlation between CIN and precipitation over ocean and over land. Unlike the histogram for ocean areas, the histogram over land is strongly skewed toward negative values, and the typical magnitude of $r$ is much greater over land than over ocean. The mean $r$ value over land is significantly different from that over ocean at the $99 \%$ confidence level. Factors causing this 
(a)

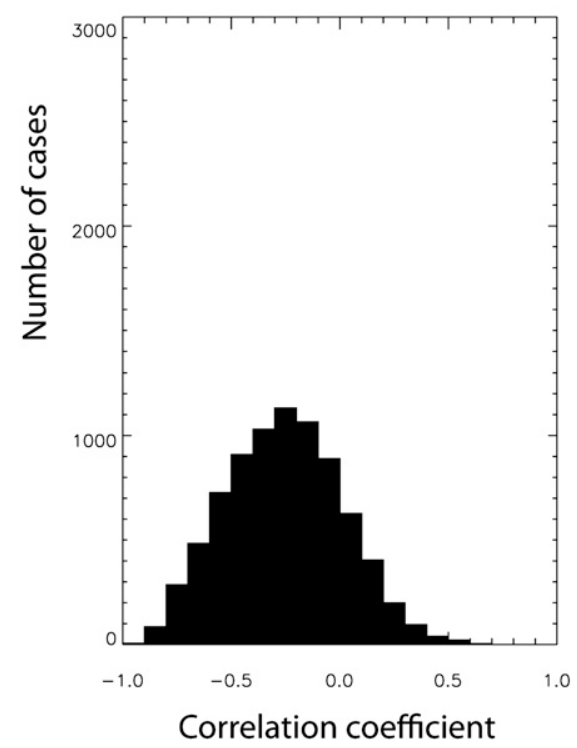

(b)

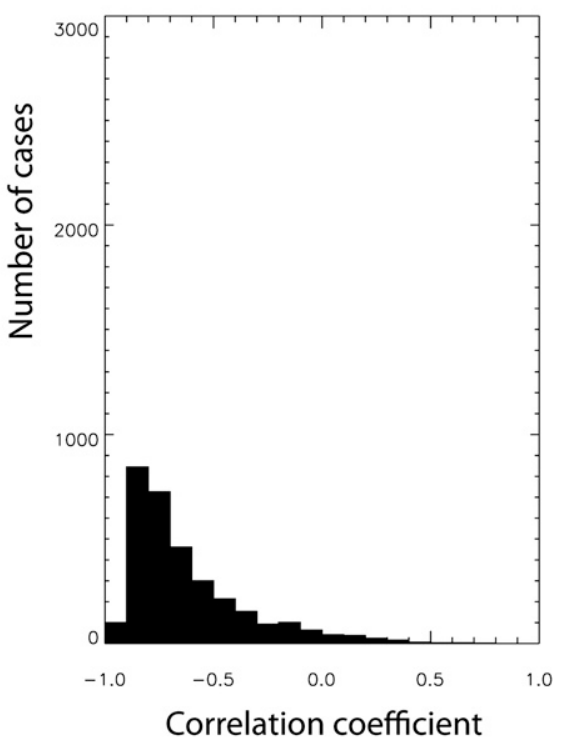

FIG. 7. Histograms of correlations between reanalysis precipitation and CIN over (a) ocean and (b) land.

dramatic difference between land and ocean may be associated with different roles of surface boundaries, atmospheric circulations, and physical and dynamical processes of precipitation over ocean and land. Those factors will be discussed in section 6 .

Meanwhile, the correlation analysis in Fig. 6 has shown that there are several regions where seasonal differences in the parameter with the highest $r^{2}$ are negligible: these are the central Pacific (PW), southeastern Asia/ the western Pacific (PW), and the central Indian Ocean (CAPE). However, the parameter with highest $r^{2}$ dramatically changes with season in South America, and there are strong spatial variations as well. This indicates that atmospheric circulations and modification of convective instability can vary significantly by season and location.

In Fig. 8, all of the parameters were overlaid with the parameter with the highest $r^{2}$ plotted first and the parameter with the lowest $r^{2}$ overlaid last. As in Fig. 5, the size of each dot is proportional to the magnitude of $r$. This shows the relative significance of all parameters at each grid point. If the three parameters have commensurate $r^{2}$ values, the color of the least significant parameter will be prominent. If two colors are prominent, the central dot represents the parameter with the smallest $r^{2}$ and the surrounding color represents the parameter with either the middle or the highest $r^{2}$ value (Fig. 6 can be used to distinguish these two possibilities).

According to Fig. 8, precipitation tends to be strongly coupled with all three parameters in certain areas, such as central and southern Africa (all months), northern Australia (all months except July), southern South America (January), central South America (July and October), India (April and October), the equatorial central Pacific (July and October), and the northern Amazon (January and April). Note that in many of these areas, correlations with respect to GHCN precipitation were substantially different (see section 4a). Scatter diagrams (convective parameters versus precipitation) are shown for four of these regions in July in Figs. 9a-d: central Africa, the eastern Maritime Continent, the equatorial central Pacific, and central Amazonia, respectively. The relationships between the convective parameters and precipitation are roughly linear except for over the Amazon (Fig. 9d). In all four regions, the convective parameters are also strongly correlated with each other (not shown). In these regions, physical and dynamical mechanisms are likely to control CIN, PW, CAPE, and precipitation simultaneously.

Meanwhile, there are regions in which only one or two parameters are tightly coupled with precipitation. For example, CIN is predominantly linked with precipitation in central Asia, western Europe (Fig. 9e), and central North America (Fig. 9f), and other convective parameters are not, implying that the variability of precipitation is explained primarily by variability of CIN in those areas.

A noteworthy feature is that relatively small correlations are found in the western Pacific $\left(0^{\circ}-30^{\circ} \mathrm{N}\right.$, $\left.135^{\circ} \mathrm{E}-180^{\circ}\right)$, the subtropical South Pacific convergence zone (STCZ; $\left.5^{\circ}-25^{\circ} \mathrm{S}, 160^{\circ} \mathrm{E}-140^{\circ} \mathrm{W}\right)$, central Africa 
(a) JAN

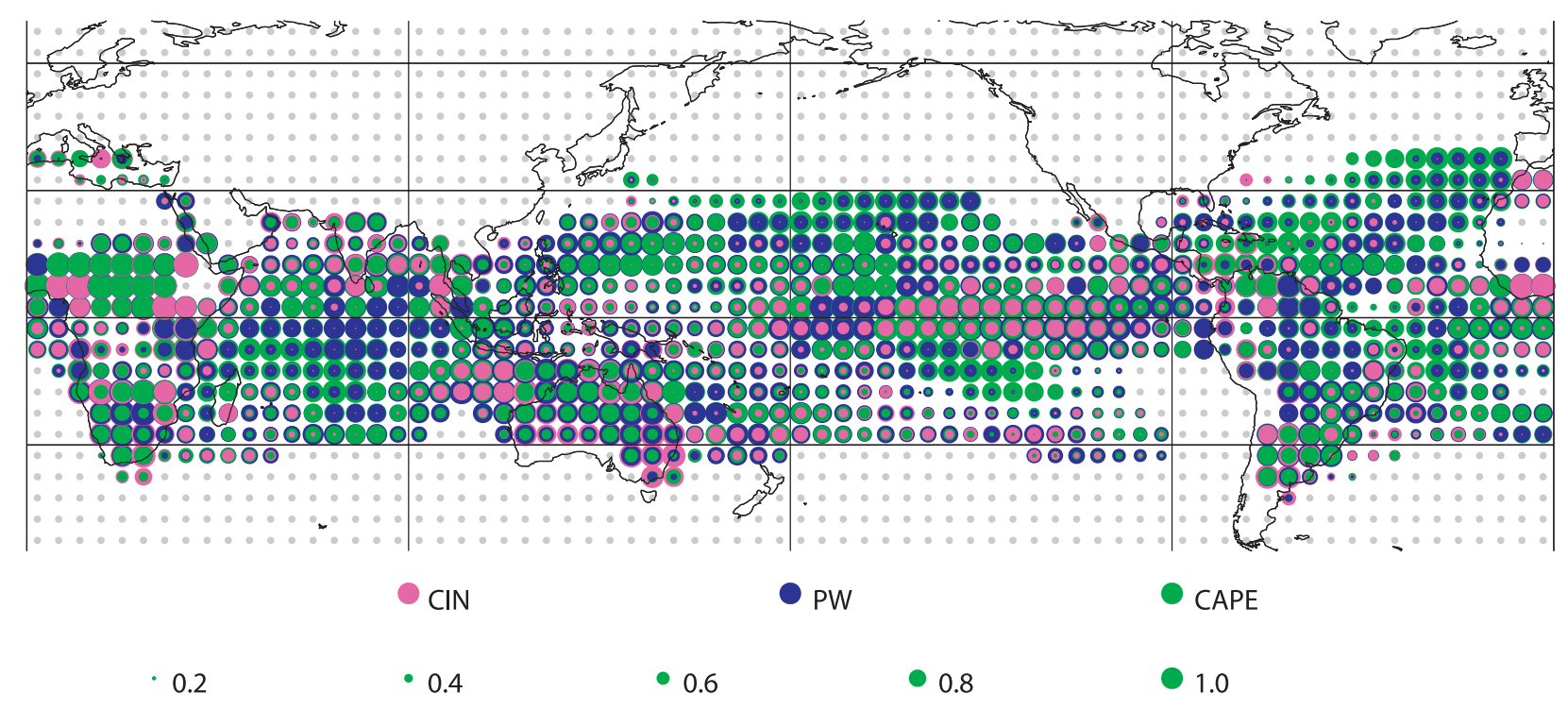

(b) APR

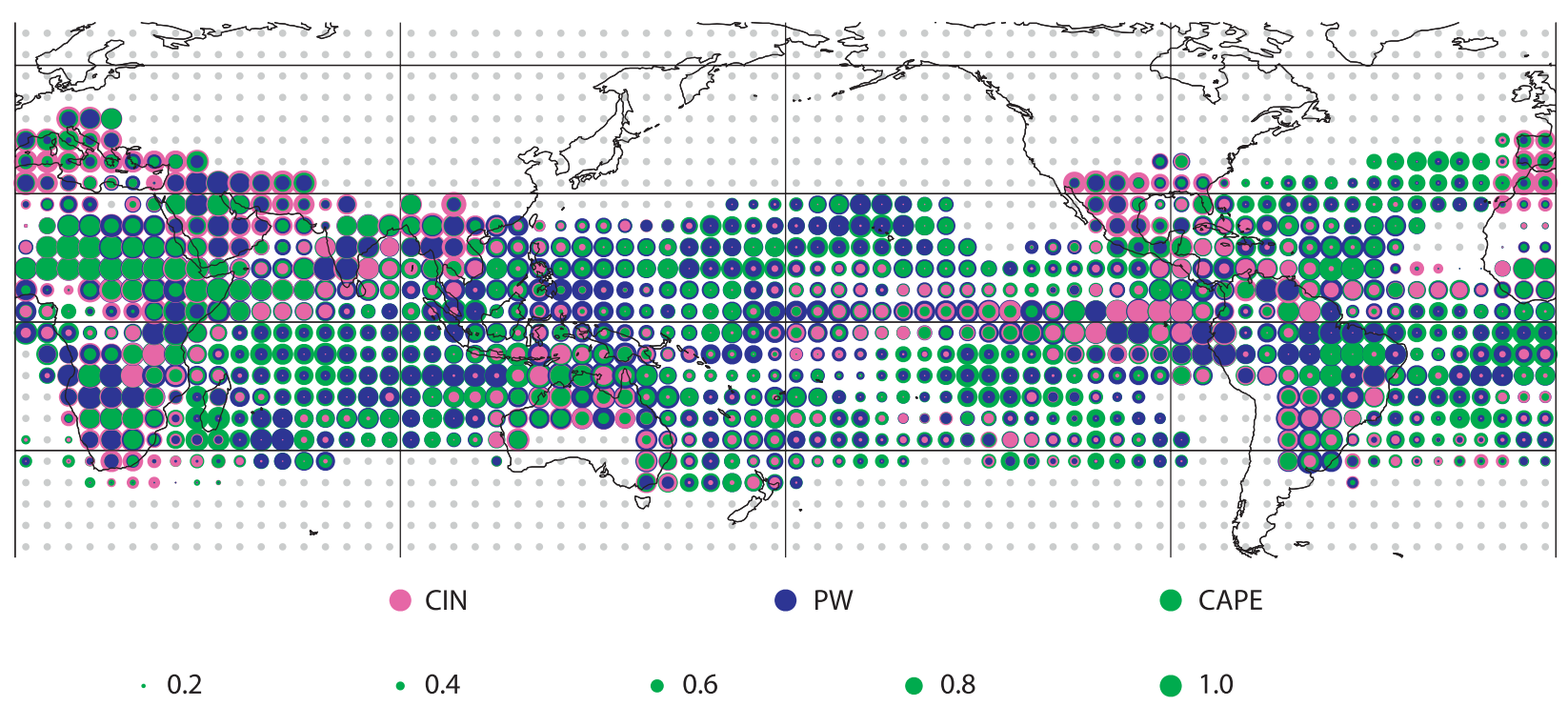

FIG. 8. Parameters (color) and magnitudes (radius) of the highest, middle, and lowest correlations overlaid in (a) January, (b) April, and (c) July with specific locations indicated for Fig. 9, and (d) October.

$\left(15^{\circ} \mathrm{S}-10^{\circ} \mathrm{N}, 5^{\circ}-20^{\circ} \mathrm{E}\right.$; January and April), the Indian Ocean $\left(5^{\circ} \mathrm{S}-10^{\circ} \mathrm{N}, 6^{\circ}-90^{\circ} \mathrm{E}\right.$; July and October), and the Caribbean and tropical Atlantic $\left(5^{\circ}-25^{\circ} \mathrm{N}, 85^{\circ}-40^{\circ} \mathrm{W}\right.$; July and October). These poor correlations in July are illustrated in Figs. $9 \mathrm{~g}$ and $9 \mathrm{~h}$ for the northern Indian Ocean and western Pacific, respectively. Many of these areas are locations of precipitation maxima. In those regions, the roles of $\mathrm{CIN}, \mathrm{PW}$, and $\mathrm{CAPE}$ in regional precipitation variability are small, implying that other parameters or processes are more significant.

\section{Tropical CAPE}

In general, the correlation between CAPE and precipitation in the tropics in Figs. 6 and 8 is much higher than would be expected from the analysis of DeMott and Randall (2004). Only part of this difference is due to the use of reanalysis precipitation instead of GHCN precipitation (Fig. 5). The remainder may be due to sampling issues associated with DeMott and Randall's use of point values for CAPE and (not 
(c) JUL

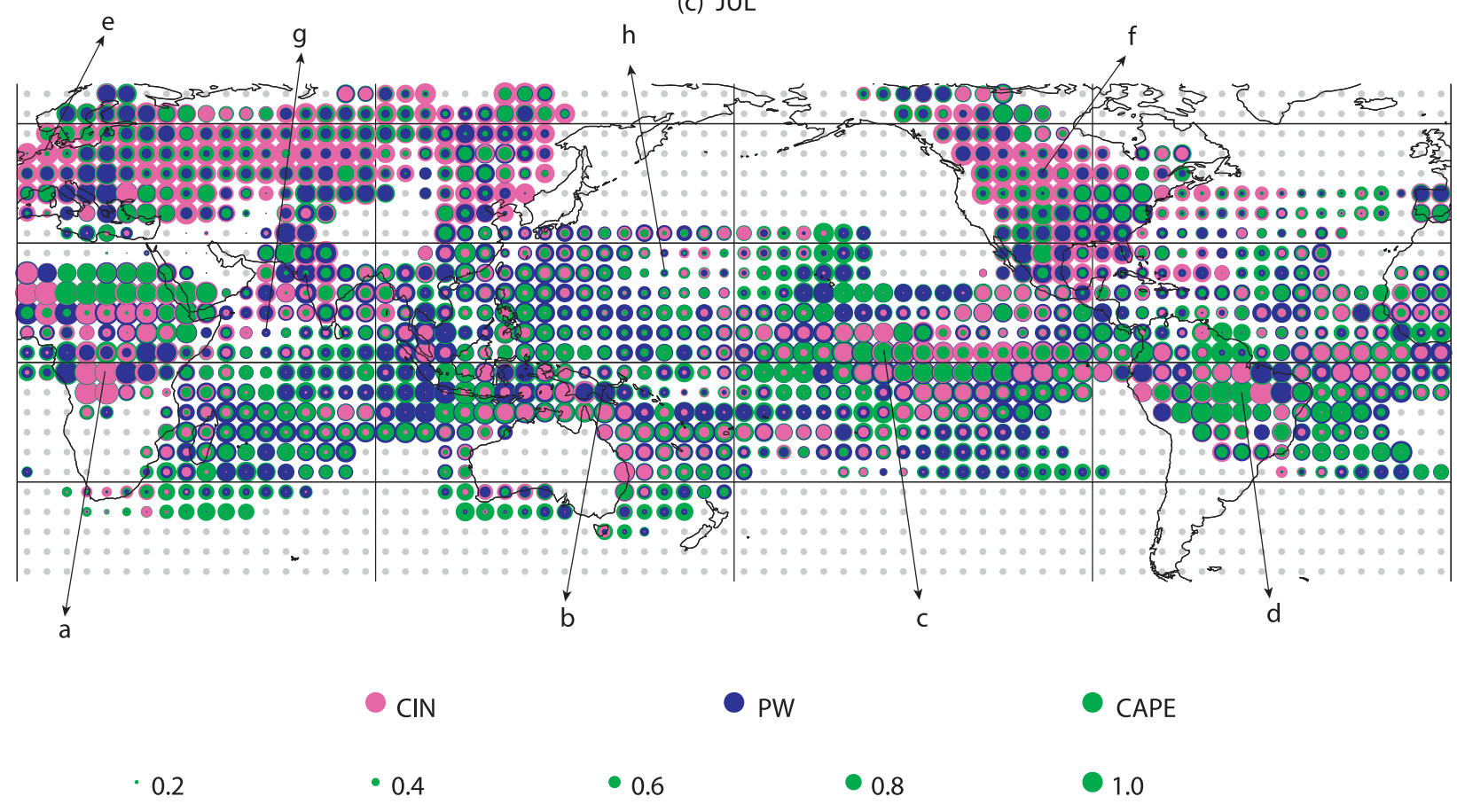

(d) OCT

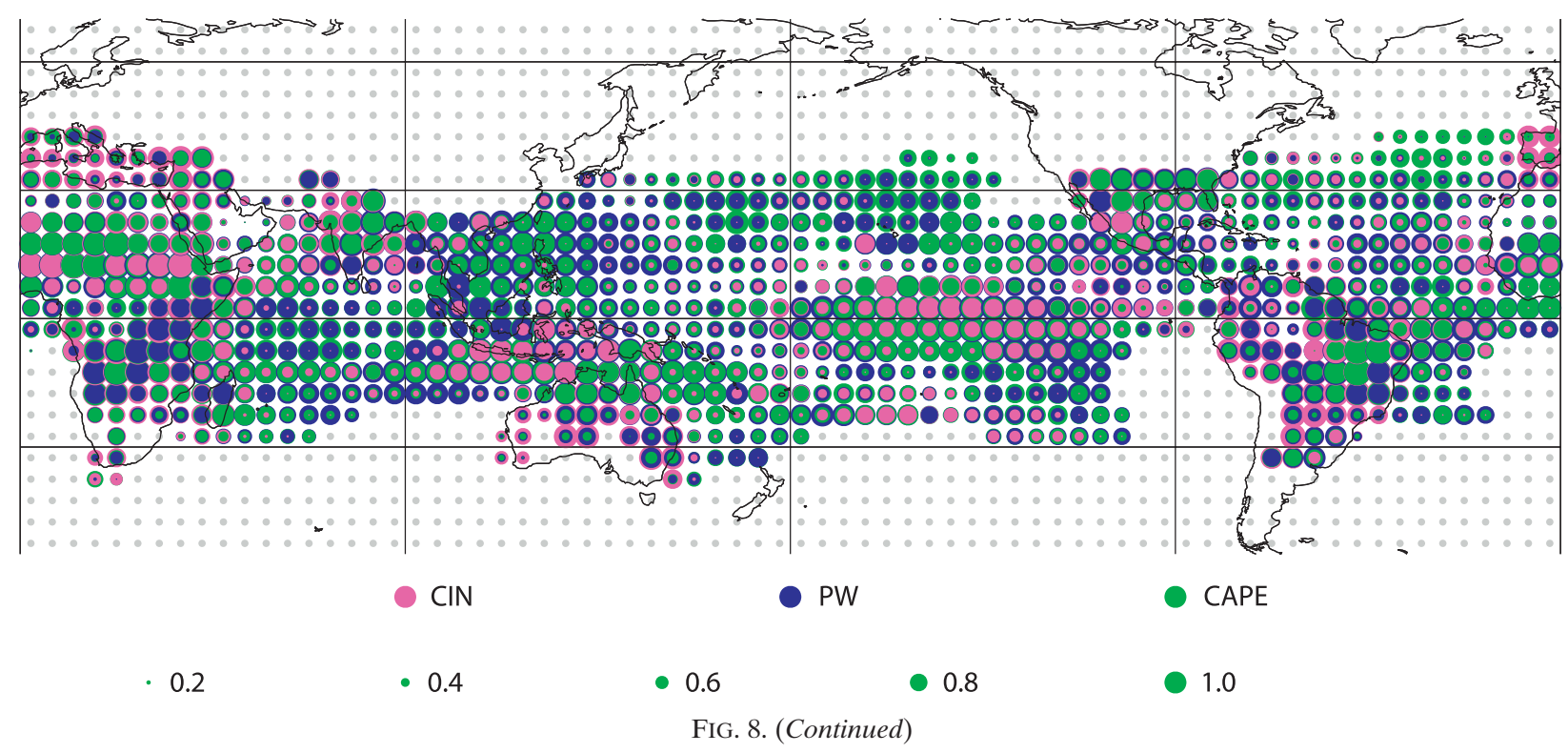

necessarily collocated) precipitation, with those point stations necessarily being on islands rather than over open water.

Over land, Ramage (1971, 101-106) showed that seasonal variations of the lapse rate in India were negatively correlated with rainfall. While CAPE is not the dominant convective parameter for reanalysis precipitation in the present analysis, its correlation is still relatively large and positive (Fig. 6c). The two results are not directly comparable since mechanisms for variations from season to season do not necessarily align with mechanisms for interannual variation. Also, lapse rate variations do not necessarily align with CAPE variations (DeMott and Randall 2004). Nonetheless, the conflicting nature of the results is cause for concern. 
(a)
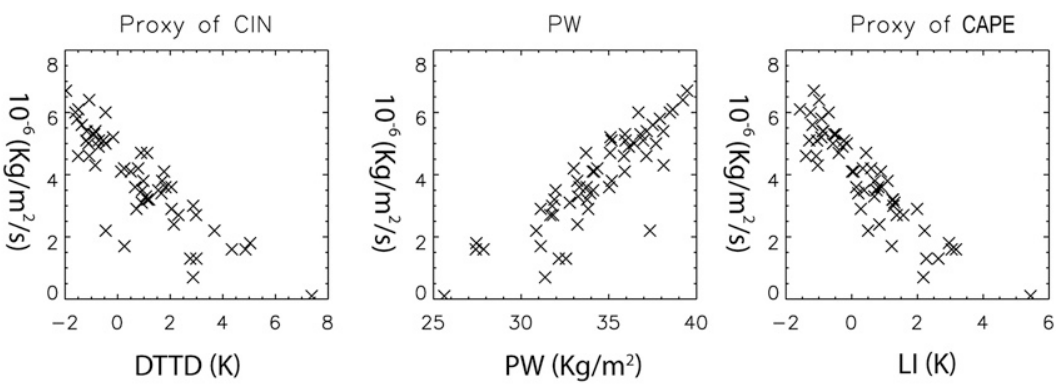

(b)
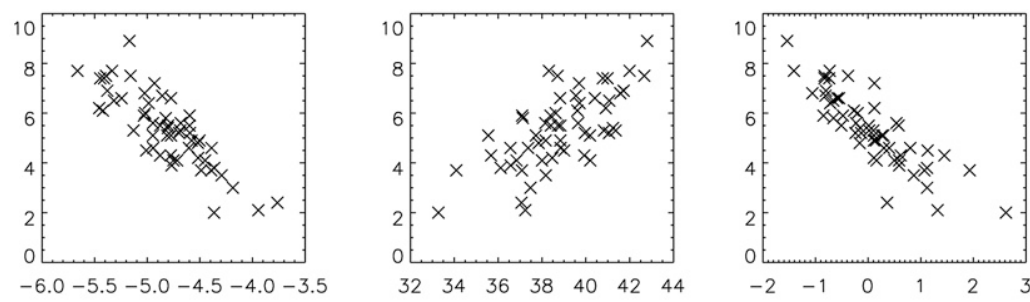

(c)
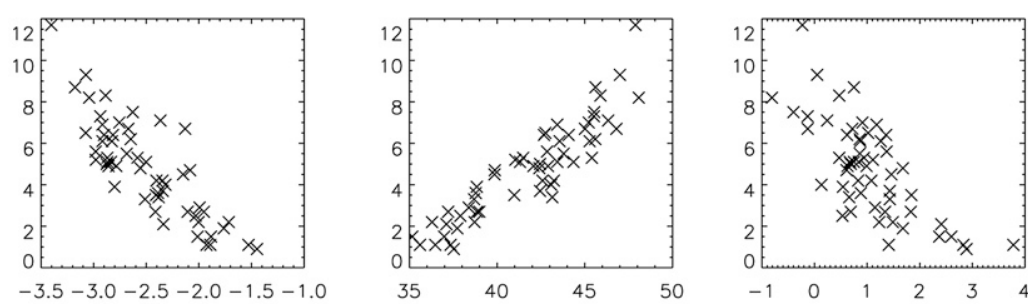

(d)
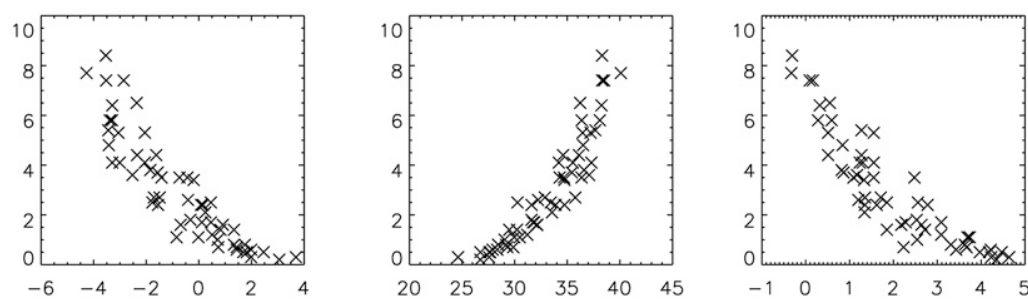

FIG. 9. Scatterplots of the convective parameters with precipitation (at the grid point) in (a) central Africa, (b) the eastern Maritime Continent, (c) the equatorial central Pacific, (d) central Amazonia, (e) western Europe, (f) central North America, (g) the northern Indian Ocean, and (h) the western Pacific in July.

To further investigate the relationship between CAPE and precipitation, we consider Singapore where the correlation between CAPE and reanalysis precipitation is large and the correlation between CAPE and GHCN precipitation is weak. Singapore is located in an area of land and water, and variations in both soundings and rain gauge precipitation might be expected to be representative of the horizontal scale inherent in the reanalysis. Convective indices computed from the Singapore data, using $1000 \mathrm{hPa}$ as an initial parcel level, do not exhibit any obvious inhomogeneities during the period chosen for examination, January 1971 through April 2009. The convective indices are compared to unadjusted monthly precipitation anomalies from seven GHCN rain gauges in nearby portions of the Malay Peninsula and Sumatra $\left(0^{\circ}-5^{\circ} \mathrm{N}, 95^{\circ}-105^{\circ} \mathrm{E}\right)$ that have at least 20 years of precipitation data available during the period of examination.

Precipitation in the region reaches a maximum in late fall and a secondary maximum in spring (Fig. 10), and average precipitation exceeds $10 \mathrm{~cm}$ at most stations and most months. Kuantan and Mersing, on the eastern coast of the Malay Peninsula, exhibit a marked December precipitation maximum, an example of the important role of wind direction and orography in controlling precipitation in the presence of conditional instability. PW at Singapore, here estimated as the 850 -hPa dewpoint to avoid irregularities in the reporting of dewpoint in the middle and upper troposphere, also has maxima in spring and late fall. CAPE and CIN, inferred from LI and DTTD, follow a quite different annual cycle, with greatest instability and weakest inhibition during the summer 
(e)

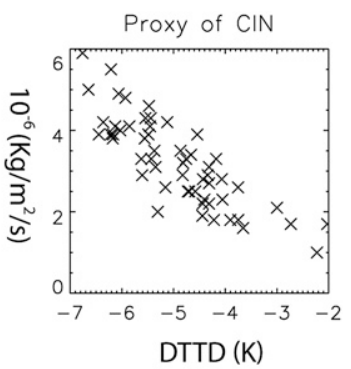

(f)

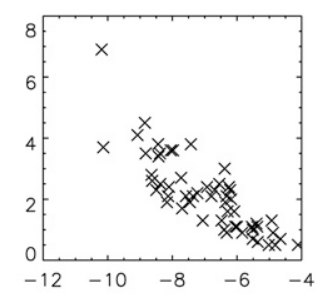

(g)

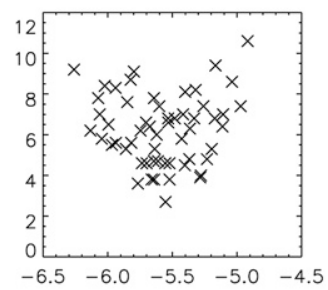

(h)

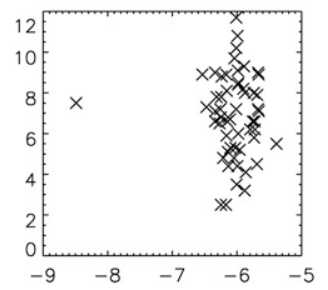

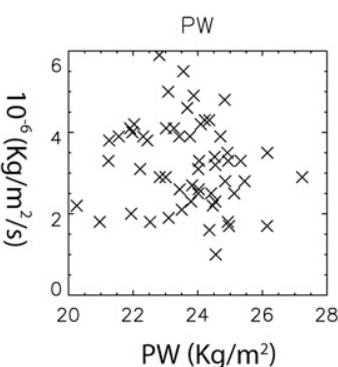
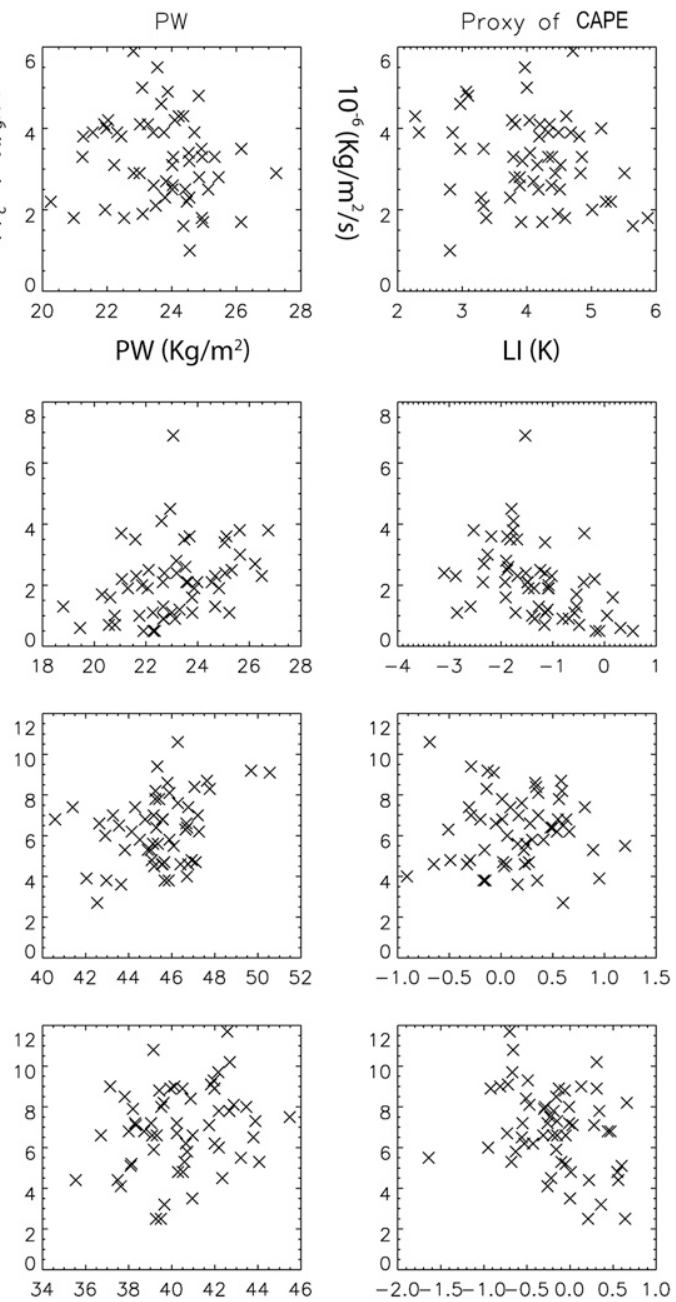

FIG. 9. (Continued) and weakest instability and greatest inhibition during the winter.

Correlations between the convective parameters and median monthly precipitation among the seven stations are shown in Fig. 11. In general, correlations with individual station precipitation values are weaker than correlations with the median. Correlations achieve 0.95 statistical significance at 0.28 . The signs of the correlations

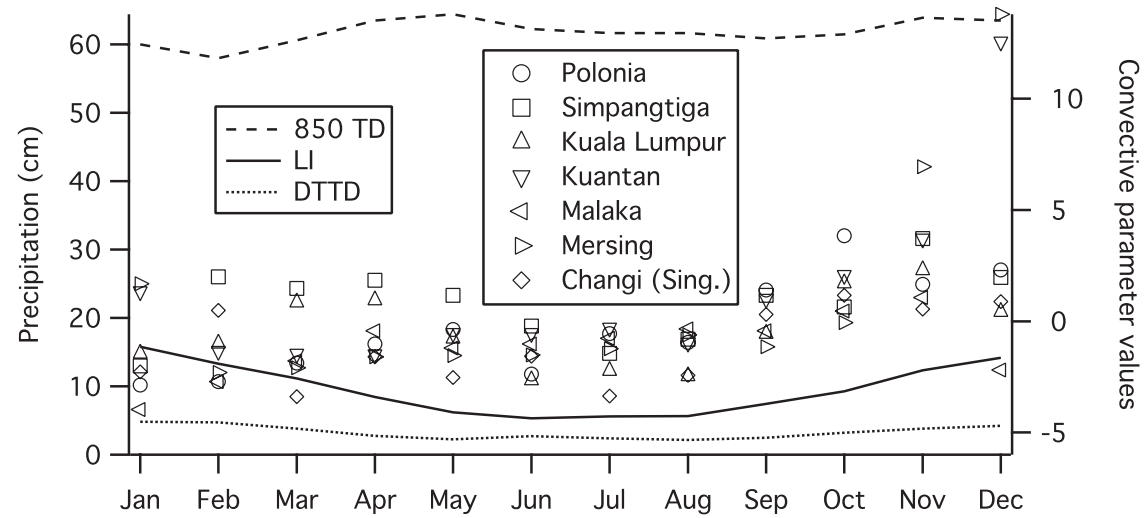

FIG. 10. Annual cycle of convective parameters in rawinsonde observations for Singapore (lines) and precipitation at nearby GHCN stations (symbols). 


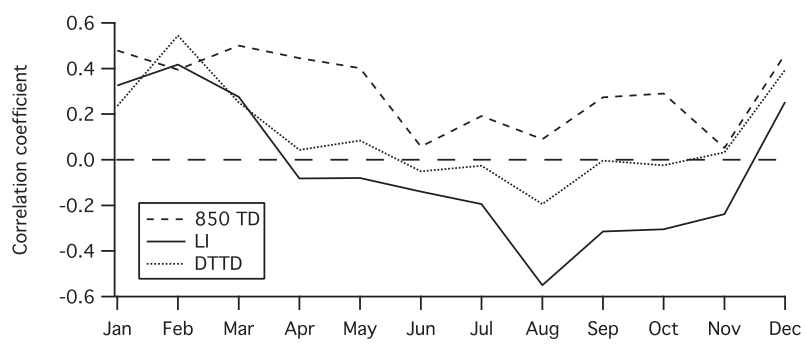

FIG. 11. Correlation between convective parameters in Singapore 0000 UTC soundings and mean precipitation at the seven stations shown in Fig. 10. The sign of the correlation is assigned to be consistent with any expected causal relationship between the convective indices and the precipitation.

are presented so that positive correlations imply the indices are favorable for convection. Statistically significant correlations are present during most months in fall, winter, and spring. The proxy for PW is positively correlated with precipitation throughout the year and is strongly correlated during the period December-May. CAPE (LI) and CIN (DTTD) also strongly favor convection during the December-March period, but are weakly or negatively correlated during other times of the year.

These results are consistent with the reanalysis correlations with GHCN precipitation in Fig. 5, which show CIN and PW moderately positively correlated during January, and only a very weak PW correlation during July. They are inconsistent with respect to correlations with reanalysis precipitation, which are positive for all parameters and months examined and are large for all except CIN in April and October (Fig. 6). This suggests that the correlations with reanalysis precipitation, while informative with respect to the reanalysis model performance characteristics, should only be taken as reflective of physical relationships present in the atmosphere where they can be independently validated with GHCN precipitation or by other means.

\section{Discussion}

The most striking result from this study, found in both GHCN and reanalysis precipitation, is that precipitation responds to its environment differently over land and ocean. The high correlation coefficient between CIN and precipitation over land suggests that CIN may be the primary environmental causal mechanism for monthly precipitation variability over land. Over the ocean, variability of precipitation tends to be associated with that of PW or CAPE. It is known that the magnitude of CIN is relatively large over land compared over the ocean (Williams and Renno 1993). First, soil moisture amplifies variations of surface dewpoint depression through flux partitioning at the surface (Rowntree and Bolton 1983; Garratt 1993; Betts et al. 1996) and affects CIN greatly over land compared to over ocean. Second, while the vertical profile of temperature in the lower troposphere is diverse over land, horizontal temperature gradients and variance of the vertical temperature profile are exceedingly weak in the free troposphere over the deep tropics, owing to the weak constraints of rotation and the consequent nonlocal nature of dynamical and convective adjustments (Charney 1963, 1969; Manabe and Strickler 1964; Manabe and Wetherald 1967; Held and Hou 1980; Bretherton and Smolarkiewicz 1989; Nakajima et al. 1992; Folkins and Braun 2003). Thus, over land the existence of a large amount of CIN tends to inhibit the initiation of convection despite substantial PW and CAPE, while over the ocean this rarely happens, and PW and CAPE are more likely to be strongly correlated with precipitation.

If precipitation is controlled by convective parameters on monthly time scales, these variables might be effective parameters for predicting precipitation on a monthly or seasonal basis. The correlation coefficients in Fig. 5 can be also considered as correlation coefficients of a regression model using a convective parameter as an independent variable. For example, when the correlation coefficient between CAPE and precipitation is $r=0.6$ at a grid point, $r^{2}=36 \%$ of the variation in precipitation is explained by CAPE. While the predictability of interannual variability of convective precipitation is low in the tropics and subtropics on a monthly time scale, even in the ENSO-dominant regions (Brankovic and Palmer 2000; Kang et al. 2004), tight couplings of convective parameters and precipitation in most of the convectionpreferred regions in this study suggest potential applications of convective parameters as a tool for predicting the intensity of monthly convective precipitation. The use of a two-parameter regression model produces even higher correlations over parts of the oceans (not shown), though not as high as the raw correlation coefficients would imply because the convective parameters are also in general correlated with each other (Emanuel et al. 1994; DeMott and Randall 2004).

\section{Summary and conclusions}

This study has examined the relationship of convective instability to precipitation over the regions where convective precipitation is preferred, and has discussed the modulation of convective instability on precipitation on a monthly basis. Three thermodynamic properties obtained or computed from reanalysis data were examined: CIN, PW, and CAPE. The lifted index (LI) and the difference between lower-tropospheric temperature 
and surface dewpoint (DTTD) were used as proxies of CAPE and CIN, respectively.

Correlations were examined with respect to both GHCN and reanalysis precipitation. The results are in general agreement over North America, Europe, central Asia, southern Africa, summertime Australia, and, in Janaury, the tropical Pacific. Larger differences are found in central Africa, India, parts of Southeast Asia and South America, and the tropical Pacific in July. A closer examination of precipitation characteristics in one particular location of disagreement confirmed that the correlations with observed precipitation were more robust than the correlations with reanalysis precipitation.

A simple correlation analysis revealed that the most significant convective parameter varies by location, that is, CIN over the summer continents in the Northern Hemisphere and Australia and PW or CAPE over the ocean and most tropical rainforests. The difference in CIN correlation over land versus over oceans is statistically significant at the $99 \%$ level. The factors driving CIN variability, and the relative importance of surface moisture and lower-tropospheric temperature, will be the subject of future investigation.

Over the ocean, the correlations tend to be rather consistent with season. However, over Africa and South America they vary substantially by season, implying that precipitation mechanisms are changing substantially as well.

In the reanalysis data, monthly mean precipitation is strongly correlated with all three parameters in parts of Africa, Australia, South America, India, the equatorial central Pacific, and the Amazon (implying, in turn, that the convective parameters are correlated among themselves), while only one or two parameters are significantly correlated with precipitation in other places. Over the western Pacific, central Africa, Indian Ocean, Caribbean, and the tropical Atlantic, all three parameters are poorly correlated with precipitation. Over those regions, the variability of monthly mean precipitation does not seem to be captured with simple convective indices. Intraseasonal variations or other aspects of the environment may play a significant role there in initiating and modulating convection.

This type of analysis of convective variability may also be useful for understanding long-term and future trends in convective precipitation, in both models (Chou and Neelin 2004) and observations (DeMott and Randall 2004). Although those aspects of this study based solely on model-derived reanalysis precipitation must be interpreted with caution, especially over the tropics, overall this study provides a useful starting point for the diagnosis of the source of monthly vari- ability of precipitation in terms of convective instability theory.

\section{REFERENCES}

Agudelo, P. A., J. A. Curry, C. D. Hoyos, and P. J. Webster, 2006: Transition between suppressed and active phases of intraseasonal oscillations in the Indo-Pacific warm pool. J. Climate, 19, 5519-5530.

Arakawa, A., and W. H. Schubert, 1974: Interaction of a cumulus cloud ensemble with the large scale environment. Part I. J. Atmos. Sci., 31, 674-701.

Betts, A. K., J. H. Ball, A. C. M. Beljaars, M. J. Miller, and P. Viterbo, 1996: The land surface-atmosphere interaction: A review based on observational and global modeling perspectives. J. Geophys. Res., 101, 7209-7225.

Bhowmik, S. K. R., S. Sen Roy, and P. K. Kundu, 2008: Analysis of large-scale conditions associated with convection over the Indian monsoon region. Int. J. Climatol., 28, 797-821.

Biasutti, M., D. S. Battisti, and E. S. Sarachik, 2004: Mechanisms controlling the annual cycle of precipitation in the tropical Atlantic sector in an atmospheric GCM. J. Climate, 17, 47084723.

Brankovic, C., and T. N. Palmer, 2000: Seasonal skill and predictability of ECMWF PROVOST ensembles. Quart. J. Roy. Meteor. Soc., 126, 2035-2067.

Brenner, I. S., 2004: The relationship between meteorological parameters and daily summer rainfall amount and coverage in west-central Florida. Wea. Forecasting, 19, 286-300.

Bretherton, C. S., and P. K. Smolarkiewicz, 1989: Gravity waves, compensating subsidence, and entrainment and detrainment around cumulus clouds. J. Atmos. Sci., 46, 740-759.

— M. E. Peters, and L. E. Back, 2004: Relationships between water vapor path and precipitation over the tropical oceans. J. Climate, 17, 1517-1528.

Charney, J. G., 1963: A note on large-scale motions in the tropics. J. Atmos. Sci., 20, 607-609.

- 1969: A further note on large-scale motions in the tropics. J. Atmos. Sci., 26, 182-185.

Chen, M., P. Xie, J. E. Janowiak, and P. A. Arkin, 2002: Global land precipitation: A 50-yr monthly analysis based on gauge observations. J. Hydrometeor., 3, 249-266.

Chiang, J. C. H., and A. H. Sobel, 2002: Tropical tropospheric temperature variations caused by ENSO and their influence on the remote tropical climate. J. Climate, 15, 2616-2631.

Chou, C., and J. D. Neelin, 2004: Mechanisms of global warming impacts on regional tropical precipitation. J. Climate, 17, 2688-2701.

DeMott, C. A., and D. A. Randall, 2004: Observed variations of tropical convective available potential energy. J. Geophys. Res., 109, D02102, doi:10.1029/2003JD003784.

Doswell, C. A., III, 1987: The distinction between large-scale and mesoscale contribution to severe convection: A case study example. Wea. Forecasting, 2, 3-16.

Emanuel, K. A., J. D. Neelin, and C. S. Bretherton, 1994: On largescale circulations in convecting atmospheres. Quart. J. Roy. Meteor. Soc., 120, 1111-1143.

Eshel, G., and B. F. Farrell, 2001: Thermodynamics of eastern Mediterranean rainfall variability. J. Atmos. Sci., 58, 87-92.

Folkins, I., and C. Braun, 2003: Tropical rainfall and boundary layer moist entropy. J. Climate, 16, 1807-1820.

Frueh, B., and V. Wirth, 2007: Convective available potential energy (CAPE) in mixed phase cloud conditions. Quart. J. Roy. Meteor. Soc., 133, 561-569. 
Fu, R., B. Zhu, and R. Dickinson, 1999: How do the atmosphere and land surface influence the seasonal changes of convection in tropical Amazon? J. Climate, 12, 1306-1321.

Garratt, J. R., 1993: Sensitivity of climate simulations to landatmospheric boundary layer treatments-A review. J. Climate, 6, 419-449.

Goddard, L., and N. E. Graham, 1999: The importance of the Indian Ocean for simulating rainfall anomalies over eastern and southern Africa. J. Geophys. Res., 104, 19 099-19 116.

Grell, G. A., 1993: Prognostic evaluation of assumptions used by cumulus parameterizations. Mon. Wea. Rev., 121, 764-787.

Held, I. M., and A. Y. Hou, 1980: Nonlinear axially symmetric circulations in a nearly inviscid atmosphere. J. Atmos. Sci., 37, $515-533$.

Horel, J. D., and J. M. Wallace, 1981: Planetary-scale atmospheric phenomena associated with the Southern Oscillation. Mon. Wea. Rev., 109, 813-829.

Huang, X. L., B. J. Soden, and D. L. Jackson, 2005: Interannual covariability of tropical temperature and humidity: A comparison of model, reanalysis data and satellite observation. Geophys. Res. Lett., 32, L17808, doi:10.1029/2005GL023375.

Janowiak, J. E., A. Gruber, C. R. Kondragunta, R. E. Livezey, and G. J. Huffman, 1998: A comparison of the NCEP-NCAR reanalysis precipitation and the GPCP rain gauge-satellite combined dataset with observational error considerations. J. Climate, 11, 2960-2979.

Kalnay, E., and Coauthors, 1996: The NCEP/NCAR 40-Year Reanalysis Project. Bull. Amer. Meteor. Soc., 77, 437-471.

Kang, I.-S., J. Y. Lee, and C.-K. Park, 2004: Potential predictability of summer mean precipitation in a dynamical seasonal prediction system with systematic error correction. J. Climate, 17, 834-844.

Lanicci, J. M., and T. T. Warner, 1991: A synoptic climatology of the elevated mixed-layer inversion over the southern Great Plains in spring. Part I: Structure, dynamics, and seasonal evolution. Wea. Forecasting, 6, 198-213.

Li, H., and B. Chen, 2005: The evolution of precipitable water associated with the Asian and Australian monsoons as revealed from MODIS/SSMI, ECMWF, and NCEP reanalysis data sets. Geophys. Res. Lett., 32, L10811, doi:10.1029/2005GL022570.

Manabe, S., and R. F. Strickler, 1964: Thermal equilibrium of the atmosphere with a convective adjustment. J. Atmos. Sci., 21, 361-385.

, and R. T. Wetherald, 1967: Thermal equilibrium of the atmosphere with a given distribution of relative humidity. J. Atmos. Sci., 24, 241-259.

Mason, S. J., and L. Goddard, 2001: Probabilistic precipitation anomalies associated with ENSO. Bull. Amer. Meteor. Soc., 82, 619-638.
Nakajima, K., Y. Y. Hayashi, and Y. Abe, 1992: A study of the "runaway greenhouse effect" with a one-dimensional radiativeconvective model. J. Atmos. Sci., 49, 2256-2266.

Parsons, D. B., K. Yoneyama, and J. L. Redelsperger, 2000: The evolution of the tropical western Pacific atmosphere-ocean system following the arrival of a dry intrusion. Quart. J. Roy. Meteor. Soc., 126, 517-548.

Ramage, C. S., 1971: Monsoon Meteorology. Academic Press, $296 \mathrm{pp}$.

Raymond, D. J., G. B. Raga, C. S. Bretherton, J. Molinari, C. Lopez-Carrillo, and Z. Fuchs, 2003: Convective forcing in the intertropical convergence zone of the eastern Pacific. J. Atmos. Sci., 60, 2064-2082.

Roads, J., and A. Betts, 2000: NCEP-NCAR and ECMWF reanalysis surface water and energy budgets for the Mississippi river basin. J. Hydrometeor., 1, 88-94.

Ropelewski, C. F., and M. S. Halpert, 1987: Global and regional scale precipitation patterns associated with the El Niño/ Southern Oscillation. Mon. Wea. Rev., 115, 1606-1625.

Rowntree, P. R., and J. A. Bolton, 1983: Simulation of the atmospheric response to soil moisture anomalies over Europe Quart. J. Roy. Meteor. Soc., 109, 501-526.

Sato, T., and F. Kimura, 2003: A two-dimensional numerical study on diurnal cycle of mountain lee precipitation. J. Atmos. Sci., 60, 1992-2003.

Sherwood, S. C., 1999: Convective precursors and predictability in the tropical western Pacific. Mon. Wea. Rev., 127, 2977-2991.

Sultan, B., and S. Janicot, 2003: The West African monsoon dynamics. Part II: The "preonset" and "onset" of the summer monsoon. J. Climate, 16, 3407-3427.

Thompkins, A. M., and G. C. Craig, 1998: Radiative-convective equilibrium in a three-dimensional cloud-ensemble model Quart. J. Roy. Meteor. Soc., 124, 2073-2097.

Trenberth, K. E., and C. J. Guillemot, 1998: Evaluation of the atmospheric moisture and hydrological cycle in the NCEP/ NCAR reanalyses. Climate Dyn., 14, 213-231.

Williams, E., and N. Renno, 1993: An analysis of the conditional instability of the tropical atmosphere. Mon. Wea. Rev., 121, 21-36.

Zveryaev, I. I., and P.-S. Chu, 2003: Recent climate changes in precipitable water in the global tropics as revealed in National Centers for Environmental Prediction/National Center for Atmospheric Research reanalysis. J. Geophys. Res., 108, 4311, doi:10.1029/2002JD002476.

, and R. P. Allan, 2005: Water vapor variability in the tropics and its links to dynamics and precipitation. J. Geophys. Res., 110, D21112, doi:10.1029/2005JD006033. 